\title{
Selection of candidate genes controlling veraison time in grapevine through integration of meta-QTL and transcriptomic data
}

\author{
Pietro Delfino ${ }^{1,2}$, Sara Zenoni ${ }^{1}$, Zahra Imanifard ${ }^{1}$, Giovanni Battista Tornielli ${ }^{1}$ and Diana Bellin ${ }^{1 *}$ (D)
}

\begin{abstract}
Background: High temperature during grape berry ripening impairs the quality of fruits and wines. Veraison time, which marks ripening onset, is a key factor for determining climatic conditions during berry ripening. Understanding its genetic control is crucial to successfully breed varieties more adapted to a changing climate. Quantitative trait loci (QTL) studies attempting to elucidate the genetic determinism of developmental stages in grapevine have identified wide genomic regions. Broad scale transcriptomic studies, by identifying sets of genes modulated during berry development and ripening, also highlighted a huge number of putative candidates.

Results: With the final aim of providing an overview about available information on the genetic control of grapevine veraison time, and prioritizing candidates, we applied a meta-QTL analysis for grapevine phenologyrelated traits and checked for co-localization of transcriptomic candidates. A consensus genetic map including 3130 markers anchored to the grapevine genome assembly was compiled starting from 39 genetic maps. Two thousand ninety-three QTLs from 47 QTL studies were projected onto the consensus map, providing a comprehensive overview about distribution of available QTLs and revealing extensive co-localization especially across phenology related traits. From 141 phenology related QTLs we generated 4 veraison meta-QTLs located on linkage group (LG) 1 and 2, and 13 additional meta-QTLs connected to the veraison time genetic control, among which the most relevant were located on LG 14, 16 and 18. Functional candidates in these intervals were inspected. Lastly, taking advantage of available transcriptomic datasets, expression data along berry development were integrated, in order to pinpoint among positional candidates, those differentially expressed across the veraison transition.
\end{abstract}

Conclusion: Integration of meta-QTLs analysis on available phenology related QTLs and data from transcriptomic dataset allowed to strongly reduce the number of candidate genes for the genetic control of the veraison transition, prioritizing a list of 272 genes, among which 78 involved in regulation of gene expression, signal transduction or development.

Keywords: Grapevine, Phenology, QTL, Meta-QTL, Transcriptomics, Veraison, Grape berry development

\footnotetext{
* Correspondence: diana.bellin@univr.it

'Department of Biotechnology, University of Verona, Strada le Grazie 15,

37134 Verona, Italy

Full list of author information is available at the end of the article
}

(c) The Author(s). 2019 Open Access This article is distributed under the terms of the Creative Commons Attribution 4.0 International License (http://creativecommons.org/licenses/by/4.0/), which permits unrestricted use, distribution, and reproduction in any medium, provided you give appropriate credit to the original author(s) and the source, provide a link to the Creative Commons license, and indicate if changes were made. The Creative Commons Public Domain Dedication waiver (http://creativecommons.org/publicdomain/zero/1.0/) applies to the data made available in this article, unless otherwise stated. 


\section{Background}

Grapevine is one of the most important fruit crops grown worldwide. It provides berries to be used as fresh fruit, raisins or for wine making, a key socio-economic sector for many countries.

Grapevine's developmental cycle is described by three main phenological stages. Budbreak represents the onset of the vegetative growth. Flowering starts the vine reproductive growth, leading, when fertilisation takes place, to berry formation. Veraison, the onset of the berry ripening process, is the stage when major changes occur in berries. Indeed, while organic acids and a few other compounds already accumulate in berries before this stage, starting from veraison time berries switch from being small, hard and acidic to a status where they become larger, softer, coloured and accumulate sugars and flavours or aromatic compounds with a decrease in organic acids content. All these events largely determine wine quality [1]. Finally, when berries meet required sugar and acidity content they are harvested, even though maturity, also called ripening, cannot be considered as true a phenological stage, due to the difficulties in establishing uniform criteria for different varieties [2].

Grapevine phenology is driven by temperature and, being also under genetic control, different varieties differ in their phenological timing, due to morphological and physiological characteristics [3]. Accordingly, the suitability of each variety to a given area has been defined by climatic factors that limit their geographic distribution, with the finest wines associated with geographically distinct viticulture regions [4]. Veraison date determines climatic conditions during the ripening. Too high temperatures lead to negative effects, which include the reduction of final anthocyanin content in berries [5], with consequences on the visual aspect of the fruit and red wines, the decoupling of ripening parameters (i.e., excess sugar content but low acidity, $[6,7])$, an inadequate pool of polyphenolic compounds and incomplete development of flavours. Long-term studies on climatology and grapevine phenology demonstrated that global warming has already affected, in several areas, the onset and duration of phenological events, with an acceleration in their timing [4, 8-14]. Further changes and their impacts on quality have been also modelled either globally or for the most important grape growing areas worldwide, highlighting that impacts of climate change on viticulture suitability is expected to become substantial, at least for some regions [2, 15-19]. Adaptation by taking into account agronomic practices or migration of vineyards is unlikely, and incorporation through cross-breeding of traits for the control of phenology beside temperature resilience is recommended in the long term $[2,15,20,21]$.

With the final aim of breeding varieties better adapted to future climatic conditions many teams have attempted to elucidate the genetic determinism of phenology, and in particular veraison time, by applying QTL studies, finding regions in the grapevine genome linked to observed variation including a large number of genes [22-26]. An interesting opportunity to summarize available QTL information and refine their genomic location, by comparing individual experiments narrowing down original intervals, comes from QTL meta-analysis [27, 28]. Indeed, QTLs detected in different experiments and located in a given region of a chromosome could possibly represent several estimations of one single shared QTL. This hypothesis can be tested by appropriate statistical tools that indicate the most likely number of 'real' QTLs underlying co-located QTLs. The resulting meta-QTLs are expected to better refine the boundaries of the causative genomic intervals by integrating information from different studies. This approach was first applied to study flowering time in maize [29]. Subsequent positional cloning and association mapping analysis revealed two genes in meta-QTL intervals effectively involved in modulating flowering time [30-32] confirming meta-analysis as useful tool for predicting candidates and developing markers for breeding. Since then QTL meta-analyses have become popular in the literature to score QTLs of huge breeding potential and towards QTL validation and/or prioritization of candidates. Lately, meta-analysis has been successfully applied in many crops like rice [33], cotton [34], potato [35], soybean [36], bean [37] and many others. However, this approach has so far not been applied in grapevine.

Technological advances and the availability of a highquality draft of the grapevine genome sequence [38] have encouraged characterizations of berry development at the transcriptomic level [39-48]. Beside identifying specific transcripts modulated during berry development, these studies revealed that a major transcriptomic shift is associated to the veraison transition [44, 49]. Integrated network analysis of expression data allowed genes to be classified according to their correlation with interaction partners, and to define "switch genes," likely playing a key role in this major transition [44, 46]. Lately, by detailed analysis of expression profiles in two different varieties, two rapid and successive transitions at the timing of the molecular reprogramming associated to veraison were defined, including positive and negative molecular "biomarkers" [48].

The number of candidate genes putatively involved in the genetic control of the veraison transition either underlying veraison QTLs, or emerging from transcriptomic studies, is huge. With the final aim of defining a prioritizing strategy we developed a consensus genetic map from 39 independent maps and, following QTLs projection, performed a meta-analysis of co-located veraison QTLs or of veraison QTLs and other phenology QTLs. Then, by anchoring to the grapevine genome assembly and integrating information from transcriptomic 
studies, we selected a set of putative key regulators for the grapevine veraison transition.

\section{Results \\ Selection of grape QTLs for integration and scoring of phenology related ones}

All published grapevine QTL studies up to October 2018 were collected from the literature to retrieve those including suitable information for integration of data from independent studies/populations. This resulted in the selection of 42 publications, reporting 47 different QTL maps from more than 80 available (Additional file 1) [22-26, 50-86]. These QTL studies exploited a total of 24 different cross populations, constituted on average by 157 offspring (number of offspring ranging from 74 to 265). Cross populations were mainly F1, with the only exception of two populations obtained by self-pollination and one obtained by selfing an F1 [56, 67, 68]. A large number of cross populations (14) were derived by crossing Vitis vinifera with hybrids or other Vitis species, but a number of intra-vinifera crosses was also reported.

These selected QTL studies included 2093 QTLs for 354 different phenotypes. A detailed list of all scored phenotypes, grouped according to the study and including the QTL short name used in the relative reference as well as a short description, is provided in Additional file 2. Each measured phenotype/QTL was manually attributed to its most related trait, for which the phenotype was considered to be a descriptor, and traits were arbitrarily grouped in 8 main trait categories. An overview of the plant traits in grapevine currently more characterized by these studies, grouped according to the eight different trait categories, is given in Additional file 3. Number of QTLs for each trait as well as number of studies considering each trait are shown. The trait for which the highest number of QTLs is currently available in the literature is berry metabolites (Additional file 3a). This is expected since high throughput metabolomic approaches can easily produce a large amount of data. However, the overall most scored trait across QTL studies was berry weight (scored in 12 independent studies), while trait categories most addressed by independent studies so far have been phenology and pathogen resistance (Additional file 3b, number of independent studies per category indicated in brackets).

Interestingly, 184 QTLs among those included in the selected studies were belonging to the trait category phenology, derived from 12 publications. This category includes 5 main traits namely bud burst, flowering, veraison, ripening times and length of intervals among the different stages. Table 1 provides details about these phenology QTLs including the reference in which they were found, the short name attributed to the originally scored phenotype in each of these publications and the distribution across the different traits' type. Among these, 54 QTLs derived from 6 studies were related to the main trait veraison.

\section{Building of a grapevine consensus genetic map}

All 35 genetic maps used in the selected QTL studies (see genetic map references in Additional file 1) were used as input for the construction of a consensus map in BioMercator v4.2 software [87]. A grapevine reference map, developed from the integration of 5 different genetic maps [88], was also included, as well as 3 further available grapevine genetic maps $[22,89,90]$.

Common markers made the construction of a consensus possible for each of the 19 grapevine chromosomes with no residual conflicts (Additional files 4 and 5). The consensus map consisted of 19 linkage groups, corresponding to the 19 grapevine chromosomes, including 3130 markers with a total length of $1922 \mathrm{cM}$ and an average number of markers and length per linkage group of 164 and 101 centiMorgan (cM) respectively. The number of markers shared by at least two maps was 1209 , corresponding to $38.63 \%$ of the total markers, with an average of 63 shared markers per linkage group (Table 2). The number of maps used for the construction of each linkage group varied from 26 (LG 11) to 39 (LGs 1, 2, 4, 5, 10,12, 17, 18), due to the different number of markers shared among maps (Table 2, Additional file 6).

Marker density was not equally distributed among the consensus, with peaks in putative centromeric positions similarly to those found in original maps. However, comparison of markers order between the single component maps and consensus map revealed a high level of correlation (Additional file 7). Spearman's rank correlation values of pairwise comparisons were significantly high for all maps but two, possibly due to the low number of shared markers.

The consensus genetic map was connected to the genome annotation through the use of an anchor file including marker's physical position, recovered as explained in the methods section. Upon removal of markers showing incongruent or not unique physical positions 713 markers (on average 38 markers per LG) were physically mapped on the 12X.v2 assembly of the grapevine genome [91]. Their physical coordinates are also included in the map file Additional file 4. Among these markers, 480 (67\%) were shared by at least two original maps, and the majority $(513,72 \%)$ were microsatellite markers.

\section{Distribution of grapevine QTLs on the consensus genetic map}

All QTLs from the 47 selected QTL studies (Additional file 1) were projected onto the consensus map to build QTL consensus maps for each trait (Additional file 8). In 
Table 1 Published grapevine phenology related QTLs included in the analysis

\begin{tabular}{|c|c|c|c|}
\hline QTL study reference & Trait & $\begin{array}{l}\text { QTL Short_ } \\
\text { Name }^{a}\end{array}$ & $\begin{array}{l}\mathrm{N}^{\circ} \text { of QTLs included } \\
\text { in the study }\end{array}$ \\
\hline [52] Ban et al. 2016 & ripening & ta, ssc & 5 \\
\hline \multirow[t]{5}{*}{$\begin{array}{l}\text { [53] Bayo Canha, } \\
\text { PhD thesis } 2015\end{array}$} & $\begin{array}{l}\text { bud } \\
\text { break }\end{array}$ & $\mathrm{Sp}$ & 6 \\
\hline & flowering & FW & 3 \\
\hline & interval & $\mathrm{Vr}-\mathrm{Rp}$ & 1 \\
\hline & ripening & $\begin{array}{l}\text { Tss/Ac, Ac, Ma, } \\
\text { Tar/Ma, Rp }\end{array}$ & 11 \\
\hline & veraison & $\mathrm{Vr}$ & 2 \\
\hline \multirow[t]{4}{*}{$\begin{array}{l}\text { [58] Carreño Ruiz, } \\
\text { PhD thesis } 2012\end{array}$} & $\begin{array}{l}\text { bud } \\
\text { break }\end{array}$ & BB & 2 \\
\hline & flowering & $\mathrm{FT}$ & 7 \\
\hline & ripening & RT & 4 \\
\hline & veraison & VT & 6 \\
\hline \multirow{4}{*}{$\begin{array}{l}\text { [22] Costantini et al. } \\
2008\end{array}$} & flowering & $\mathrm{FT}$ & 4 \\
\hline & interval & $F-R, F-V, V-R$ & 6 \\
\hline & ripening & $\mathrm{R}$ & 1 \\
\hline & veraison & VP, VT & 4 \\
\hline \multirow[t]{2}{*}{$\begin{array}{l}\text { [23] Duchêne et al. } \\
2012\end{array}$} & $\begin{array}{l}\text { bud } \\
\text { break }\end{array}$ & $B-B$ & 5 \\
\hline & interval & $B-F, F-V$ & 17 \\
\hline \multirow{2}{*}{$\begin{array}{l}\text { [25] Fechter et al. } \\
2014\end{array}$} & flowering & FBL, FS & 27 \\
\hline & veraison & VT & 4 \\
\hline \multirow[t]{3}{*}{$\begin{array}{l}\text { [24] Grzeskowiak } \\
\text { et al. } 2013\end{array}$} & $\begin{array}{l}\text { bud } \\
\text { break }\end{array}$ & BB & 1 \\
\hline & flowering & $\mathrm{FB}$ & 3 \\
\hline & veraison & VB, VE & 20 \\
\hline [75] Mejía et al. 2007 & ripening & $\mathrm{RDA}$ & 3 \\
\hline [83] Viana et al. 2013 & ripening & At, Bpc & 9 \\
\hline [86] Zhao et al. 2016 & ripening & Cma & 5 \\
\hline [85] Zhao et al. 2015 & ripening & SSC & 2 \\
\hline \multirow{2}{*}{$\begin{array}{l}\text { [26] Zyprian et al. } \\
2016\end{array}$} & interval & $F-V$ & 8 \\
\hline & veraison & VT & 18 \\
\hline
\end{tabular}

${ }^{\mathrm{a}}$ The original short name of phenology QTLs included in the analysis is indicated. QTLs for veraison are highlighted in bold. QTL short name abbreviations are as following: ta total acid, ssc solubile solids concentration, Sp Sprouting, Fw Flowering, Vr-Rp Veraison-ripening period, Tss/Ac Ratio of total soluble solids to total acidity, Ac Total acidity, Ma Malic acid, Tar/Ma Ratio of tartaric acid to malic acid, $R p$ Ripening, $V r$ Veraison, BB Bud break, $F T$ Flowering time, $R T$ Ripening time, $V T$ Veraison time, F- $R$ Flowering ripening interval, $F$ - $V$ Flowering-veraison interval, $V$ - $R$ Veraison ripening interval, $R$ Ripening, VP Veraison period, $B-B$ February-budbreak/Bud, $B-F$ Budbreakflowering/Flo, FBL Time of full bloom, FS Start of flowering, FB Flowering beginning, $V B$ Veraison beginning, $V E$ Veraison end, RDA Ripening date, At Tartaric acid, $B p c$ Brix per cluster, $C m a$ Fruit maturation period. Further details about phenotype scoring for each QTL can be found in the Additional file 2, Additional file 19 or in the indicated original publications.

total 1899 QTLs (91\%) could be successfully plotted while 194 could not be projected, due to lack of anchoring markers. The percentage of plotted QTLs was comparable across the different traits, ranging from
82 to $100 \%$. Only for the traits ripening time, fertility and black rot resistance the number of plotted QTLs was lower (75, 65 and 65\% respectively).

To aid spotting QTLs emerging independently in more studies, circular plots of consensus QTL maps were prepared for each trait grouped by trait category. Plots for all trait categories except phenology are provided in Additional file 9, while the phenology category plot is provided in Fig. 1. Careful inspection revealed that the trait with the highest number of co-located QTLs from independent studies, highlighted by bars on the outer side of chromosomes, was downy mildew resistance (Additional file 9e). QTLs located on LG 1, 4, 5, 6, 7, 8, $10,12,14,17$ and 18 were all confirmed by more studies, with up to 5 studies mapping QTLs to an overlapping region on LG 18. However, for all other pathogen resistance traits only one QTL was discovered by different studies, namely the QTL on LG 15 for powdery mildew resistance found in three independent studies. In a similar way, several QTLs for the trait anthocyanin, on LG 1, $2,4,6,7,10,12$ and 17 , were all confirmed by independent studies with the most consistently found QTL mapping on LG 2. However, also for this category no other trait revealed confirmed QTLs, at least considering these studies, since the overlapping QTLs shown in Additional file $9 \mathrm{~d}$ for other traits in this category all come from one study. For abiotic stress and cluster related traits categories, overlaps among QTLs from independent studies were also few and involved just one trait inside the category (Additional file 9a and b). Instead, for the categories berry morphology, seeds related traits and vegetative traits more than one traits had overlapping QTLs mapped in independent studies (Additional file 9c, f and g). Importantly phenology was overall the category for which the number of QTLs' kind confirmed by independent studies was the highest. Indeed, in this category four ripening QTLs were independently found at similar genetic loci by independent studies, i.e. on LG 1, 2, 3, 18, six flowering QTLs were consistently mapped to LG $1,2,7,14,17$ and 19, while for veraison and floweringveraison interval 3 and 1 confirmed QTLs were mapped respectively on LG 1,2 and 16 or on LG 16 (Fig. 1). However, for each of these QTLs the confirmation was only based on few studies, ranging from 2 to a maximum of 3 (Additional file 10).

\section{Narrowing down of candidates for veraison time by meta- QTL analyses}

For the purpose of performing a meta-analysis on veraison co-located QTLs independently mapped by more studies, thus reducing their genetic intervals, the list of veraison QTLs projected onto the consensus map (Additional file 8) was manually curated, as explained in the material and methods section, to avoid over- 
Table 2 Consensus genetic map features

\begin{tabular}{|c|c|c|c|c|c|}
\hline$\overline{L G}$ & $\mathrm{~N}^{\circ}$ of markers & $\mathrm{N}^{\circ}$ unique markers ${ }^{a}$ & $\begin{array}{l}\mathrm{N}^{\circ} \text { markers in at } \\
\text { least two maps }\end{array}$ & Length (cM) & $\begin{array}{l}\mathrm{N}^{\circ} \text { of individual } \\
\text { maps integrated }\end{array}$ \\
\hline I & 214 & 130 & 84 & 95.68 & 39 \\
\hline$\|$ & 130 & 71 & 59 & 89.73 & 39 \\
\hline III & 135 & 92 & 43 & 92.03 & 37 \\
\hline IV & 161 & 101 & 60 & 93.36 & 39 \\
\hline V & 206 & 150 & 56 & 70.64 & 39 \\
\hline $\mathrm{Vl}$ & 139 & 93 & 46 & 90.72 & 38 \\
\hline VII & 204 & 124 & 80 & 82.09 & 38 \\
\hline VIII & 167 & 88 & 79 & 95.72 & 37 \\
\hline IX & 128 & 77 & 51 & 85.01 & 35 \\
\hline$x$ & 168 & 93 & 75 & 141.87 & 39 \\
\hline$X I$ & 90 & 38 & 52 & 72.64 & 26 \\
\hline$X \|$ & 211 & 153 & 58 & 143.13 & 39 \\
\hline XIII & 156 & 89 & 67 & 113 & 37 \\
\hline XIV & 202 & 118 & 84 & 94.79 & 37 \\
\hline$X V$ & 128 & 86 & 42 & 93.44 & 37 \\
\hline $\mathrm{XVI}$ & 126 & 74 & 52 & 68.7 & 35 \\
\hline$X V \|$ & 130 & 76 & 54 & 104.47 & 39 \\
\hline$X V I I I$ & 275 & 172 & 103 & 148.93 & 39 \\
\hline$X I X$ & 160 & 96 & 64 & 146.03 & 37 \\
\hline Total & 3130 & 1921 & 1209 & 1921.98 & \\
\hline
\end{tabular}

${ }^{\mathrm{a}}$ Markers present in only one input genetic map

representation of any trait. We selected 35 veraison QTLs from 6 studies [22, 24-26, 53, 58]. Meta-analysis was applied to LG 1 and 2, where overlapping QTLs were retained after pruning. Our meta-analysis resulted in the identification of 4 veraison meta-QTLs (ver), one located on LG 1 (ver_1.1) and three on LG 2 (ver_2.1, ver_2.2 and ver_2.3) (Table 3, Fig. 1). More in detail, the veraison meta-QTL on LG 1 was derived from 2 original colocated QTLs while on LG 2 each resulted from the integration of 5 to 7 original co-located QTLs. Average confidence interval $(\mathrm{CI})$ was $3.5 \mathrm{cM}$ ranging from $1.2 \mathrm{cM}$ for ver_2.3 to $5.1 \mathrm{cM}$ for ver_2.1, which was the largest one. On LG 1 the original CI covered by QTLs was reduced from $23.9 \mathrm{cM}$ to $4.3 \mathrm{cM}$ (5.6 times) by the metaanalysis. On LG 2 the reduction of CI was 5 times overall, with a strongest effect on the ver_2.3 meta-QTL. $R^{2}$ values of meta-QTLs were all higher than $10 \%$. In particular, ver 2.2 was the most relevant, explaining up to $34 \%$ of total variance.

Inspection of the consensus QTL map for the whole phenology category (Fig. 1) revealed extensive colocalization also across the different traits (i.e. co-location of veraison and ripening QTLs, etc.). Co-location of veraison QTLs with other phenology QTLs was indeed highly significant compared to a random distribution $\left(\chi^{2}\right.$-test, $p<0.01)$ [92]. Overlapping phenology QTLs could represent several estimates of a single QTL affecting more developmental stages, which would justify the attempt to identify consensus QTLs across different phenology traits. In agreement with such an option, a meta-analysis for veraison QTLs and overlapping QTLs for other phenology traits was applied by considering 141 phenology QTLs retained after plotting and pruning of those in the consensus map (Additional file 8), similarly to what was previously described. When applied to veraison QTLs mapping on LG 1 and LG 2, this approach identified meta-QTLs largely overlapping with previously reported veraison meta-QTLs (Additional file 11). Therefore, with the final aim of reducing the number of genes underlying veraison QTLs, the same strategy was applied to veraison QTLs on other LGs, and this identified 13 further indicative metaQTL regions potentially relevant for the genetic control of veraison (Table 4, Fig. 1). We named these additional meta-QTLs as ver/ph to clarify that they were obtained from veraison QTLs overlapping with other phenology related QTLs. Among these, two meta-QTLs on LG 16 were particularly relevant, explaining up to 35 and $38 \%$ of total phenotypic variance.

In conclusion, after anchoring to the genome, the number of genes underlying original veraison QTLs was narrowed down by applying the meta-QTL analysis, by a factor of 3.7. By including alternative phenology related 


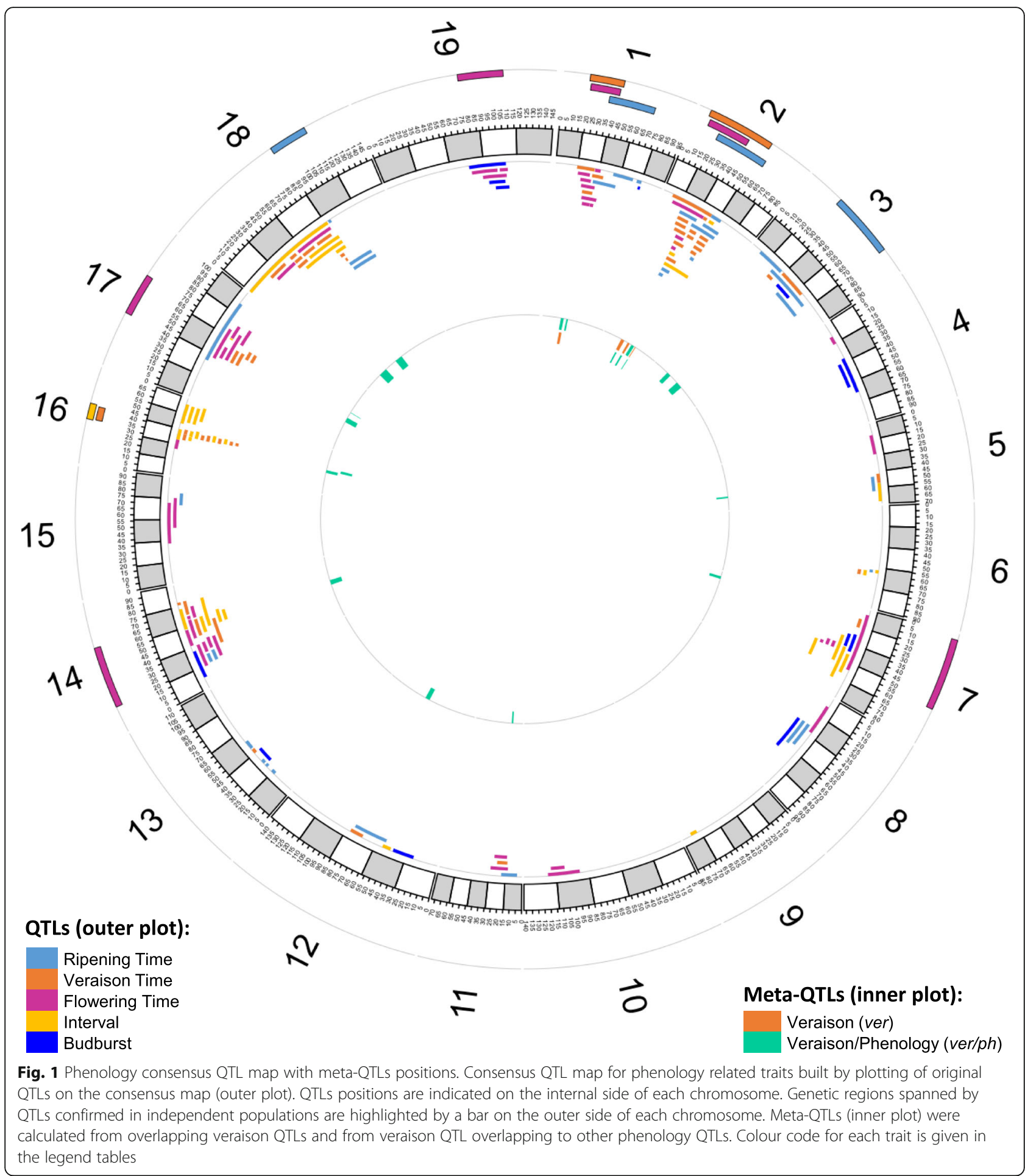

traits, we also reduced the number of positional candidates at further locations, even though to a lesser extent (2.2 times) (Fig. 2). However, we should consider that this last approach relies on the assumption of shared genetic control, which could lead to skipping relevant candidates, if not verified. Lists of candidate genes in ver meta-QTLs and ver/ph meta-QTLs intervals, with the corresponding CRIBIv1 annotation (http://genomes.cribi. unipd.it/gb2/gbrowse/public/vitis_vinifera_v2/), are given in Additional files 12 and 13 respectively.

To validate our meta-QTL procedure a similar analysis was applied to QTLs projected on the consensus for the anthocyanins trait. We focused on overlapping QTLs mapping on LG 2. Indeed, berry colour genetic control 
Table 3 Meta-QTLs calculated from overlapping veraison QTLS

\begin{tabular}{|c|c|c|c|c|c|c|c|c|c|c|c|c|}
\hline LG & $\begin{array}{l}\text { Meta- } \\
\text { QTL }\end{array}$ & $\begin{array}{l}\text { Peak Pos. } \\
\text { (cM) }\end{array}$ & $\begin{array}{l}\text { Mean } \\
R^{2}\end{array}$ & $\begin{array}{l}\text { Start } \\
(\mathrm{cM})\end{array}$ & $\begin{array}{l}\text { End } \\
\text { (cM) }\end{array}$ & $\begin{array}{l}\text { Start } \\
(\mathrm{bp})^{\mathrm{a}}\end{array}$ & $\begin{array}{l}\text { End } \\
(\mathrm{bp})^{\mathrm{a}}\end{array}$ & $\begin{array}{l}\text { Pos } \\
\text { Candidates }^{a}\end{array}$ & $\begin{array}{l}\text { Original QTLs co- } \\
\text { located }^{\text {b }}\end{array}$ & $\begin{array}{l}\text { QTL Studies } \\
\text { (Populations) }^{\text {b }}\end{array}$ & QTL $^{c}$ & $\operatorname{Ref}^{d}$ \\
\hline I & $\begin{array}{l}\text { ver } \\
1.1\end{array}$ & 31.29 & 0.11 & 29.15 & 33.43 & $\begin{array}{l}2,510 \\
506\end{array}$ & $\begin{array}{l}3,254 \\
952\end{array}$ & 78 & 2 & 2 & VT & {$[25,26]$} \\
\hline \multirow[t]{3}{*}{$\|$} & $\begin{array}{l}\text { ver } \\
2.1\end{array}$ & 31.34 & 0.17 & 28.79 & 33.89 & $\begin{array}{l}4,029 \\
921\end{array}$ & $\begin{array}{l}5,344 \\
816\end{array}$ & 147 & 7 & 2 & $\mathrm{VB}, \mathrm{Vr}$ & {$[24,53]$} \\
\hline & $\begin{array}{l}\text { ver } \\
2.2\end{array}$ & 41.55 & 0.13 & 40.00 & 43.30 & $\begin{array}{l}5,717 \\
649\end{array}$ & $\begin{array}{l}7,154 \\
894\end{array}$ & 96 & 5 & 3 & $\begin{array}{l}\text { Vr, VB, } \\
\text { VE, VT }\end{array}$ & $\begin{array}{l}{[22,24,} \\
53]\end{array}$ \\
\hline & $\begin{array}{l}\text { ver } \\
2.3\end{array}$ & 53.47 & 0.34 & 52.88 & 54.07 & $\begin{array}{l}13,336 \\
750\end{array}$ & $\begin{array}{l}16,677 \\
137\end{array}$ & 94 & 5 & 3 & $\mathrm{Vr}, \mathrm{VE}, \mathrm{VP}$ & $\begin{array}{l}{[22,24,} \\
53]\end{array}$ \\
\hline
\end{tabular}

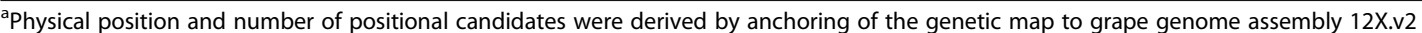

${ }^{b}$ Both number of original QTLs for the meta-QTL calculation as well as the number of independent populations from which the overlapping QTLs were found are given.

${ }^{\mathrm{C}}$ The kind of overlapping veraison QTLs used for the analysis is indicated. Veraison QTLs are highlighted in bold. QTL short name abbreviations are as following: $V r$ Veraison, VT Veraison time, VP Veraison period, VB Veraison beginning, VE Veraison end. Further details about phenotypes scoring can be found in the Additional file 2, Additional file 19 or in the indicated original publications.

${ }^{\mathrm{d}}$ Reference of the study in which the QTLs included in the meta-QTL analysis were found

Table 4 Meta-QTLs calculated from veraison QTLs overlapping with other phenology QTLS

\begin{tabular}{|c|c|c|c|c|c|c|c|c|c|c|c|c|}
\hline LG & $\begin{array}{l}\text { Meta- } \\
\text { QTL }\end{array}$ & $\begin{array}{l}\text { Peak Pos. } \\
\text { (cM) }\end{array}$ & $\begin{array}{l}\text { Mean } \\
\mathrm{R}^{2}\end{array}$ & $\begin{array}{l}\text { Start } \\
\text { (cM) }\end{array}$ & $\begin{array}{l}\text { End } \\
\text { (cM) }\end{array}$ & $\begin{array}{l}\text { Start } \\
(\mathrm{bp})^{\mathrm{a}}\end{array}$ & $\begin{array}{l}\text { End } \\
(b p)^{a}\end{array}$ & $\begin{array}{l}\text { Pos } \\
\text { Candidates }^{a}\end{array}$ & $\begin{array}{l}\text { Original QTLs co- } \\
\text { located }^{\text {b }}\end{array}$ & $\begin{array}{l}\text { QTL Studies } \\
\text { (Populations) }^{\text {b }}\end{array}$ & $\mathrm{QTL}^{\mathrm{c}}$ & Ref. $^{d}$ \\
\hline \multirow[t]{2}{*}{ III } & $\begin{array}{l}\text { ver/ph } \\
3.1\end{array}$ & 27.67 & 0.15 & 24.43 & 30.92 & $\begin{array}{l}560 \\
404\end{array}$ & $\begin{array}{l}1,647 \\
064\end{array}$ & 138 & 5 & 3 & VT, SSC, Bpc & $\begin{array}{l}{[58,83,} \\
85]\end{array}$ \\
\hline & $\begin{array}{l}\text { ver/ph } \\
3.2\end{array}$ & 50.42 & 0.14 & 45.30 & 55.54 & $\begin{array}{l}5,903 \\
464\end{array}$ & $\begin{array}{l}10,894 \\
193\end{array}$ & 288 & 4 & 3 & $\begin{array}{l}\text { VT, SSC, Bpc, } \\
\text { BB }\end{array}$ & $\begin{array}{l}{[58,83,} \\
85]\end{array}$ \\
\hline V & $\begin{array}{l}\text { ver/ph } \\
5.1\end{array}$ & 50.97 & 0.09 & 49.77 & 52.18 & $\begin{array}{l}16,799 \\
689\end{array}$ & $\begin{array}{l}19,536 \\
797\end{array}$ & 111 & 3 & 2 & $\mathrm{VT}, \mathrm{F}-\mathrm{V}, \mathrm{Ma}$ & {$[26,53]$} \\
\hline VII & $\begin{array}{l}\text { ver/ph } \\
7.1\end{array}$ & 9.59 & 0.16 & 7.58 & 11.60 & $\begin{array}{l}1,087 \\
707\end{array}$ & $\begin{array}{l}1,552 \\
842\end{array}$ & 59 & 2 & 2 & VT, FW & {$[53,58]$} \\
\hline$X I$ & $\begin{array}{l}\text { ver/ph } \\
11.1\end{array}$ & 16.15 & 0.11 & 15.01 & 17.30 & $\begin{array}{l}2,934 \\
932\end{array}$ & $\begin{array}{l}3,356 \\
851\end{array}$ & 50 & 4 & 2 & $\begin{array}{l}\text { FBL, FS, Tar/ } \\
\text { Ma, VT }\end{array}$ & {$[25,53]$} \\
\hline$X I I$ & $\begin{array}{l}\text { ver/ph } \\
12.1\end{array}$ & 77.85 & 0.19 & 74.31 & 81.40 & $\begin{array}{l}23,793 \\
458\end{array}$ & $\begin{array}{l}24,155 \\
112\end{array}$ & 27 & 2 & 2 & VT, RT & {$[26,58]$} \\
\hline XIV & $\begin{array}{l}\text { ver/ph } \\
14.1\end{array}$ & 55.03 & 0.22 & 51.45 & 58.62 & $\begin{array}{l}22,441 \\
297\end{array}$ & $\begin{array}{l}24,645 \\
689\end{array}$ & 157 & 7 & 4 & B-F, FS, FT, vT & $\begin{array}{l}{[23,25,} \\
26,58]\end{array}$ \\
\hline \multirow[t]{2}{*}{$X \mathrm{Vl}$} & $\begin{array}{l}\text { ver/ph } \\
16.1\end{array}$ & 34.70 & 0.31 & 32.53 & 36.88 & $\begin{array}{l}14,012 \\
548\end{array}$ & $\begin{array}{l}16,583 \\
139\end{array}$ & 126 & 4 & 2 & $\mathrm{~F}-\mathrm{V}, \mathbf{V T}$ & {$[22,26]$} \\
\hline & $\begin{array}{l}\text { ver/ph } \\
16.2\end{array}$ & 38.49 & 0.38 & 36.49 & 40.50 & $\begin{array}{l}16,503 \\
904\end{array}$ & $\begin{array}{l}17,318 \\
604\end{array}$ & 51 & 5 & 2 & $\mathrm{~F}-\mathrm{V}, \mathbf{V T}$ & {$[23,26]$} \\
\hline \multirow[t]{2}{*}{$X V I I$} & $\begin{array}{l}\text { ver/ph } \\
17.1\end{array}$ & 48.83 & 0.13 & 45.12 & 52.54 & $\begin{array}{l}4,969 \\
509\end{array}$ & $\begin{array}{l}6,401 \\
642\end{array}$ & 113 & 6 & 3 & $\begin{array}{l}\text { FBL, FS, RDA, } \\
\text { VB }\end{array}$ & $\begin{array}{l}{[24,25,} \\
75]\end{array}$ \\
\hline & $\begin{array}{l}\text { ver/ph } \\
17.2\end{array}$ & 61.83 & 0.11 & 61.46 & 62.20 & $\begin{array}{l}8,920 \\
888\end{array}$ & $\begin{array}{l}9,063 \\
993\end{array}$ & 12 & 7 & 4 & $\begin{array}{l}\text { FBL, FS, RDA, } \\
\text { VB, F-V }\end{array}$ & $\begin{array}{l}{[24-26,} \\
75]\end{array}$ \\
\hline \multirow[t]{2}{*}{$X V I I I$} & $\begin{array}{l}\text { ver/ph } \\
18.1\end{array}$ & 34.68 & 0.17 & 28.21 & 41.15 & $\begin{array}{l}1,836 \\
848\end{array}$ & $\begin{array}{l}5,349 \\
350\end{array}$ & 322 & 2 & 2 & VT, FT & {$[26,58]$} \\
\hline & $\begin{array}{l}\text { ver/ph_ } \\
18.2\end{array}$ & 66.33 & 0.13 & 60.57 & 72.10 & $\begin{array}{l}10,927 \\
035\end{array}$ & $\begin{array}{l}15,526 \\
564\end{array}$ & 330 & 4 & 3 & VT, FT, F-V & $\begin{array}{l}{[23,26,} \\
58]\end{array}$ \\
\hline
\end{tabular}

${ }^{\mathrm{a}}$ Physical position and number of positional candidates were derived by anchoring of the genetic map to grape genome assembly $12 \mathrm{X} . \mathrm{v} 2$

${ }^{b}$ Both number of original QTLs for the meta-QTL calculation as well as the number of independent populations from which the overlapping QTLs were found are given.

${ }^{\mathrm{C}}$ The kind of overlapping phenology related QTLs used for the analysis is indicated. Veraison QTLs overlapping with other phenology QTLs are highlighted in bold. QTL short name abbreviations are as following: SSC solubile solids concentration, FW Flowering, Ma Malic acid, Tar/Ma Ratio of tartaric acid to malic acid, BB Bud break, FT Flowering time, RT Ripening time, VT veraison time, F-V Flowering-veraison interval, B-F Budbreak-flowering/Flo, FBL Time of full bloom, FS Start of flowering, $V B$ veraison beginning, RDA Ripening date, Bpc Brix per cluster. Further details about phenotypes scoring can be found in the Additional file 2 , Additional file 19 or in the indicated original publications.

${ }^{\mathrm{d}}$ Reference of the study in which the QTLs included in the meta-QTL analysis were found 
has already been elucidated and linked to two adjacent regulatory genes, the $V v M Y B A 1$ and $V v M Y B A 2$ genes, located on chromosome (Chr) 2 [93, 94]. The meta-QTL analysis on 28 overlapping QTLs derived from 5 independent studies identified 7 meta-QTLs (Additional file 14). The $V v M Y B A 1$ and $V v M Y B A 2$ genes were both included in the list of the 125 genes underlying these meta-QTLs (Additional file 15).

\section{Selection of meta-QTL candidate genes differentially expressed across veraison}

As further alternative to reduce the number of candidates and prioritize them, we integrated positional information derived from the meta-QTL approach with molecular information obtained in previous transcriptomic studies.

Firstly, the 2195 positional candidates underlying veraison meta-QTLs ver or ver/ph (Additional files 12 and 13) were explored for their expression profiles in different organs, according to the grapevine expression atlas [49]. Four hundred and thirteen genes were never expressed either in berry, rachis or seed and were thus excluded.

Transcriptomic changes in berries during development and in particular across veraison have been widely explored. Taking advantage of previous transcriptomic studies we constituted a list of molecular candidates putatively involved in the veraison time control and compared them with our remaining positional candidates. From a transcriptomic dataset including berries collected at four time points of development (pea-size, beginning to touch, softening and full ripe), in 10 different grapevine genotypes, a massive transcriptomic change was found to be associated to the veraison transition, and 1478 genes commonly differentially expressed across veraison in all genotypes, were identified [44, 46]. Moreover, a recent transcriptomic map of berry development analysing weekly gene expression in Pinot Noir over 3 years allowed to define two rapid and successive transitions at the timing of the molecular reprogramming of berry development associated to veraison and identified positive and negative molecular "biomarkers" of these transitions [48]. This RNA-Seq dataset was further inspected in this study, especially at early time points before veraison, searching for first molecular events associated to veraison by looking for the transition across which the highest number of such "biomarkers" was differentially expressed in each of the 3 years (Additional file 16). This transition represents an early stage before veraison when the transcriptomic rearrangement associated to veraison starts to occur. One thousand seven hundred forty-nine genes mainly modulated in their profiles across this transition in at least two of the 3 years were then selected. By combining these genes with the 1478 genes identified in the 10 genotypes a final list of 2850 genes, representing transcriptomic candidates for veraison time control, was created (Additional file 17).

We found that among the 1782 positional candidates located under meta-QTLs and expressed in berry, rachis or seed, 272 genes are also transcriptomic candidates (Additional file 18). In detail, 61 lays under ver metaQTLs, and include 16 genes encoding for proteins involved in regulation of gene expression, signalling or development (Table 5). Beside these, other genes belonging to functional classes like transport ( 7 genes) or carbohydrate metabolism (5 genes), like, for example, a vacuolar invertase, were found, which could also be potentially involved in the genetic control of veraison time mapped at these locations. The other 211 genes colocalized instead to ver/ph meta-QTLs. Among these, 62 were involved in regulation of gene expression, signal transduction or development according to their gene ontologies (GO) annotation (Table 5). Moreover, representatives of other relevant functional classes, mainly enzymes involved in carbohydrate metabolism or transporters for sugar related compounds, were also among candidates found at these locations.

As expected, some of the proposed candidates were previously pointed out by QTL studies or by analysis of transcriptomic profiles. However, integration of available QTLs genetic data, by meta-QTL analysis, with transcriptomic data has allowed prioritization of the huge number of candidates, reducing by about 20 and 10 times the genes proposed so far by either only genetic or transcriptomic approaches (Fig. 2). Among these genes we expect to be included, according to all available molecular information, those controlling the grapevine veraison transition.

\section{Discussion}

A classical way to dissect the genetic determinism of grape phenology has been QTL studies [22-26, 53, 58]. However, QTLs mapping often provides inconsistent results among studies, and huge genomic locations. A big advantage can derive from meta-analysis, which offers stronger evidence than individual studies, by revealing regions robustly associated with traits in multiple environments and genetic backgrounds [29, 95]. This approach has been already successfully exploited to improve and validate QTLs in several species, allowing insights into the genetic architecture of complex traits and paving the way for fine mapping and gene cloning [32, 34-37]. With this aim a genetic consensus map was built from 39 available simple sequence repeats (SSR)-based maps, including 3130 markers. By looking at marker distribution we observed they were not regularly spread along the chromosomes, but tended to concentrate in the middle regions, even though a good correlation was found with original maps. This is not surprising, reflecting a similar trend to 


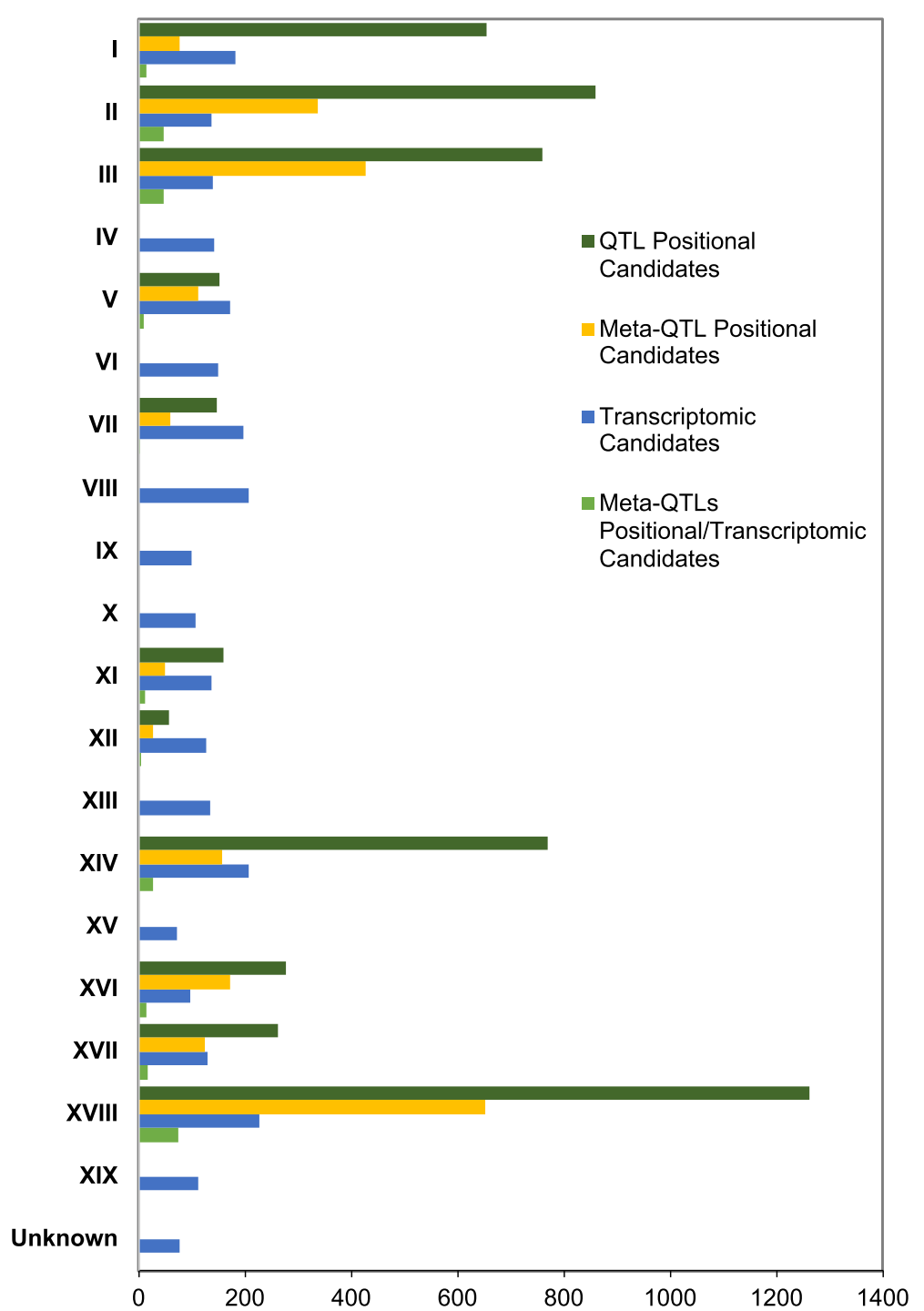

Fig. 2 Reduction in number of candidate genes for the genetic control of veraison time by the integrated approach. Number of candidate genes for veraison time control in each chromosome selected by QTLs studies, meta-QTL analysis, transcriptomic analysis or by the integrated approach is shown

original maps, due to suppression of recombination in centromeric regions. Other consensus maps already reported this drawback [35, 96]. Moreover, genetic positions of markers on the consensus arose from positions of shared markers according to the BioMercator software procedure [97], and were not based on recombination, since original genetic data are unfortunately not available from original maps. We fully agree that QTL metaanalysis would gain power and precision if raw genotypic and phenotypic data were made available. Recent advances in markers technology, with development of the next generation sequencing-based genotyping by sequencing (GBS) technology in particular, have given a strong impulse to plant genotyping, and QTL studies now rely more on dense single nucleotide polymorphism (SNP) maps. However, unshared markers do not allow for a direct genetic comparison of mapped QTLs, but require an indirect comparison through anchoring to the genome assembly. The distribution pattern of QTLs on chromosomes differs strongly between genetic and physical maps [96]. Therefore, integration directly at genetic level could aid the improving of QTL location through co-location and meta-analysis, when feasible. Further comparisons can be then undertaken to newly generated QTLs relying on high throughput SNP maps, following anchoring to the genome assembly. Taking all this into account, we concluded that the consensus map we built constitutes a valuable reference, especially to the aim of integrating available genetic information, from related QTL studies. Moreover, it will also provide a valuable instrument to enquire co-location with newly generated QTLs relying on dense SNP maps. 
Table 5 Transcriptomic candidates underlying ver meta-QTLs or ver/ph meta-QTLs selected by GO annotation for gene expression regulation, signalling or development

\begin{tabular}{|c|c|c|c|c|c|c|}
\hline Gene ID ${ }^{a}$ & Chr & Start & End & Annotation & $\mathrm{mQTL}^{\mathrm{b}}$ & $\begin{array}{l}\text { Transcriptomic } \\
\text { candidate }^{c}\end{array}$ \\
\hline VIT_01s0011g02950 & 1 & $2,618,690$ & $2,632,669$ & Zinc finger (C3HC4-type ring finger) & ver_1.1 & [48] \\
\hline VIT_01s0011g03070 & 1 & $2,751,566$ & $2,753,036$ & ERF/AP2 Gene Family (VvRAV1) & ver_1.1 & {$[44,46]$} \\
\hline VIT_01s0011g03520 & 1 & $3,190,826$ & $3,192,777$ & Constans-like 16 & ver_1.1 & {$[44,46]$} \\
\hline VIT_02s0025g04730 & 2 & $4,100,066$ & $4,103,095$ & Glyoxylate reductase & ver_2.1 & {$[44,46]$} \\
\hline VIT_02s0154g00070 & 2 & $4,804,832$ & $4,807,460$ & Abnormal floral organs & ver_2.1 & {$[44,46]$} \\
\hline VIT_02s0154g00080 & 2 & $4,813,347$ & $4,818,031$ & Multi-copper oxidase (SKU5) & ver_2.1 & {$[44,46]$} \\
\hline VIT_02s0012g00310 & 2 & $6,204,735$ & $6,223,899$ & Lon protease & ver_2.2 & {$[48]$} \\
\hline VIT_02s0012g00570 & 2 & $6,554,241$ & $6,560,259$ & $\begin{array}{l}\text { Pseudo-response regulator } 2 \\
\text { (APRR2) (TOC2) }\end{array}$ & ver_2.2 & {$[44,46]$} \\
\hline VIT_02s0012g00590 & 2 & $6,600,611$ & $6,610,281$ & Unknown protein & ver_2.2 & {$[48]$} \\
\hline VIT_02s0012g00990 & 2 & $7,043,508$ & $7,046,965$ & LOL1 (LSD ONE like 1) & ver_2.2 & {$[44,46]$} \\
\hline VIT_02s0012g01010 & 2 & $7,087,110$ & $7,089,452$ & Leucine-rich repeat & ver_2.2 & {$[48]$} \\
\hline VIT_02s0012g01040 & 2 & $7,120,118$ & $7,122,681$ & $\begin{array}{l}\text { NAC domain-containing } \\
\text { protein (VVNAC13) }\end{array}$ & ver_2.2 & {$[44,46,48]$} \\
\hline VIT_02s0033g00300 & 2 & $14,144,838$ & $14,148,929$ & myb family & ver_2.3 & {$[44,46]$} \\
\hline VIT_02s0033g00390 & 2 & $14,291,727$ & $14,292,732$ & VvMybA2 & ver_2.3 & {$[44,46]$} \\
\hline VIT_02s0033g00410 & 2 & $14,351,791$ & $14,352,807$ & VvMybA1 & ver_2.3 & {$[44,46]$} \\
\hline VIT_02s0033g00450 & 2 & $14,420,525$ & $14,421,283$ & VvMybA3 & ver_2.3 & {$[44,46,48]$} \\
\hline VIT_03s0038g00860 & 3 & 689,247 & 693,308 & $\begin{array}{l}\text { Basic Leucine Zipper Transcription } \\
\text { Factor (VvbZIP05) }\end{array}$ & ver/ph_3.1 & {$[48]$} \\
\hline VIT_03s0038g01090 & 3 & 862,995 & 863,398 & Auxin responsive SAUR protein & ver/ph_3.1 & {$[44,46]$} \\
\hline VIT_03s0038g01110 & 3 & 866,357 & 866,897 & Auxin-responsive SAUR31 & ver/ph_3.1 & {$[44,46]$} \\
\hline VIT_03s0038g01310 & 3 & 921,733 & 927,965 & Auxin responsive SAUR protein & ver/ph_3.1 & {$[48]$} \\
\hline VIT_03s0038g02130 & 3 & $1,468,239$ & $1,469,371$ & Cold shock protein-1 & ver/ph_3.1 & {$[48]$} \\
\hline VIT_03s0180g00040 & 3 & $5,973,785$ & $5,975,813$ & Cyclin D3_2 & ver/ph_3.2 & {$[48]$} \\
\hline VIT_03s0091g00210 & 3 & $6,507,392$ & $6,509,263$ & Ethylene-responsive protein & ver/ph_3.2 & {$[44,46]$} \\
\hline VIT_03s0091g00260 & 3 & $6,548,677$ & $6,549,577$ & Zinc finger protein 4 & ver/ph_3.2 & {$[44,46,48]$} \\
\hline VIT_03s0091g00870 & 3 & $7,342,165$ & $7,357,074$ & Adenylylsulfate kinase 1 (AKN1) & ver/ph_3.2 & {$[48]$} \\
\hline VIT_03s0091g01060 & 3 & $7,673,917$ & $7,675,754$ & Cyclin delta-2 & ver/ph_3.2 & {$[48]$} \\
\hline VIT_03s0088g00290 & 3 & $8,315,170$ & $8,315,924$ & Phytosulfokines PSK2 & ver/ph_3.2 & {$[44,46]$} \\
\hline VIT_03s0088g01180 & 3 & $9,438,885$ & $9,442,060$ & Proline iminopeptidase & ver/ph_3.2 & {$[48]$} \\
\hline VIT_05s0062g00760 & 5 & $19,469,712$ & $19,473,848$ & Receptor kinase RHG4 & ver/ph_5.1 & {$[48]$} \\
\hline VIT_11s0016g03640 & 11 & $2,972,017$ & $2,974,625$ & $\begin{array}{l}\text { Rac-like GTP-binding protein } \\
\text { ARAC7 (GTPase protein ROP9) }\end{array}$ & ver/ph_11.1 & {$[44,46]$} \\
\hline VIT_11s0016g03650 & 11 & $2,976,690$ & $2,979,682$ & CDKF;1 (CDK-activating kinase 1A & ver/ph_11.1 & {$[48]$} \\
\hline VIT_11s0016g03880 & 11 & $3,163,900$ & $3,169,609$ & Receptor protein kinase PERK1 & ver/ph_11.1 & {$[48]$} \\
\hline VIT_11s0016g03900 & 11 & $3,182,349$ & $3,186,809$ & AAA-type ATPase & ver/ph_11.1 & {$[48]$} \\
\hline VIT_11s0016g03940 & 11 & $3,224,068$ & $3,225,265$ & Heat shock transcription factor $\mathrm{C} 1$ & ver/ph_11.1 & {$[44,46]$} \\
\hline VIT_12s0035g02090 & 12 & $23,983,677$ & $23,999,372$ & Leucine-rich repeat family protein & ver/ph_12.1 & {$[48]$} \\
\hline VIT_12s0035g02120 & 12 & $24,046,092$ & $24,050,103$ & Unknown & ver/ph_12.1 & {$[48]$} \\
\hline VIT_14s0083g00620 & 14 & $22,672,469$ & $22,675,655$ & NIK1 (NSP- interacting kinase 1) & ver/ph_14.3 & {$[44,46]$} \\
\hline VIT_14s0083g00640 & 14 & $22,696,160$ & $22,698,346$ & Constans 2 (COL2) & ver/ph_14.3 & {$[44,46]$} \\
\hline VIT_14s0083g01030 & 14 & $23,320,331$ & $23,341,036$ & $\begin{array}{l}\text { putative MADS-box Fruitfull } 2 \\
\text { (VviFUL2) }\end{array}$ & ver/ph_14.3 & {$[44,46,48]$} \\
\hline VIT_14s0083g01110 & 14 & $23,435,436$ & $23,438,457$ & Brassinosteroid-6-oxidase & ver/ph_14.3 & {$[44,46]$} \\
\hline VIT_14s0083g01160 & 14 & $23,527,926$ & $23,532,692$ & COBRA protein & ver/ph_14.3 & {$[48]$} \\
\hline VIT_14s0083g01210 & 14 & $23,631,468$ & $23,634,185$ & feronia receptor-like kinase & ver/ph_14.3 & {$[44,46]$} \\
\hline
\end{tabular}


Table 5 Transcriptomic candidates underlying ver meta-QTLs or ver/ph meta-QTLs selected by GO annotation for gene expression regulation, signalling or development (Continued)

\begin{tabular}{|c|c|c|c|c|c|c|}
\hline Gene IDa & Chr & Start & End & Annotation & $\mathrm{mQTL} \mathrm{L}^{\mathrm{b}}$ & $\begin{array}{l}\text { Transcriptomic } \\
\text { candidate }^{c}\end{array}$ \\
\hline VIT_14s0083g01220 & 14 & $23,647,671$ & $23,648,618$ & feronia receptor-like kinase & ver/ph_14.3 & {$[44,46]$} \\
\hline VIT_14s0068g00010 & 14 & $23,691,896$ & $23,694,505$ & feronia receptor-like kinase & ver/ph_14.3 & {$[44,46]$} \\
\hline VIT_14s0068g00030 & 14 & $23,710,282$ & $23,713,253$ & feronia receptor-like kinase & ver/ph_14.3 & {$[44,46]$} \\
\hline VIT_14s0068g00040 & 14 & $23,730,955$ & $23,731,566$ & No hit & ver/ph_14.3 & {$[44,46]$} \\
\hline VIT_14s0068g00050 & 14 & $23,741,203$ & $23,741,804$ & No hit & ver/ph_14.3 & {$[44,46]$} \\
\hline VIT_14s0068g00300 & 14 & $23,997,514$ & $24,000,870$ & $\mathrm{ABRC} 5$ & ver/ph_14.3 & {$[48]$} \\
\hline VIT_14s0068g00330 & 14 & $24,046,880$ & $24,048,369$ & $\begin{array}{l}\text { PTF1 (plastid transcription factor 1) } \\
\text { TCP13 }\end{array}$ & ver/ph_14.3 & {$[44,46]$} \\
\hline VIT_14s0068g00640 & 14 & $24,438,706$ & $24,450,994$ & Acetyl-CoA synthetase & ver/ph_14.3 & {$[48]$} \\
\hline VIT_16s0022g01650 & 16 & $15,243,820$ & $15,246,842$ & Receptor serine/threonine kinase PR5K & ver/ph_16.2 & {$[48]$} \\
\hline VIT_16s0022g02230 & 16 & $16,240,572$ & $16,248,680$ & $\begin{array}{l}\text { Leucine-rich repeat receptor protein } \\
\text { kinase EXS }\end{array}$ & ver/ph_16.2 & {$[48]$} \\
\hline VIT_16s0022g02340 & 16 & $16,470,141$ & $16,475,595$ & fructokinase-2 & ver/ph_16.2 & {$[48]$} \\
\hline VIT_16s0100g00350 & 16 & $17,248,816$ & $17,261,155$ & ABC Transporter (VvTAP3 - VvABCB23) & ver/ph_16.3 & {$[48]$} \\
\hline VIT_17s0000g05020 & 17 & $5,637,669$ & $5,644,801$ & $\begin{array}{l}\text { Squamosa promoter-binding protein } \\
6 \text { (SPL6) }\end{array}$ & ver/ph_17.1 & {$[44,46]$} \\
\hline VIT_17s0000g05050 & 17 & $5,659,282$ & $5,660,704$ & COBRA-like protein 4 & ver/ph_17.1 & {$[48]$} \\
\hline VIT_17s0000g05070 & 17 & $5,676,169$ & $5,679,862$ & Phytochelatin synthetase & ver/ph_17.1 & {$[44,46,48]$} \\
\hline VIT_17s0000g05240 & 17 & $5,869,290$ & $5,885,095$ & Nuclear transport factor 2 (NTF2) & ver/ph_17.1 & {$[48]$} \\
\hline VIT_17s0000g05580 & 17 & $6,213,229$ & $6,221,132$ & Isopiperitenol dehydrogenase & ver/ph_17.1 & {$[44,46,48]$} \\
\hline VIT_18s0001g02000 & 18 & $2,438,485$ & $2,442,668$ & Zinc finger ( $\mathrm{C} 2 \mathrm{H} 2$ type) family & ver/ph_18.1 & {$[44,46,48]$} \\
\hline VIT_18s0001g02540 & 18 & $2,802,829$ & $2,805,078$ & ARR9 typeA & ver/ph_18.1 & {$[44,46]$} \\
\hline VIT_18s0001g03580 & 18 & $3,389,546$ & $3,393,993$ & Ubiquitin-fold modifier 1 precursor & ver/ph_18.1 & {$[48]$} \\
\hline VIT_18s0001g03670 & 18 & $3,422,279$ & $3,424,214$ & Zinc finger ( $\mathrm{C} 2 \mathrm{H} 2$ type) family & ver/ph_18.1 & {$[44,46]$} \\
\hline VIT_18s0001g04340 & 18 & $3,822,948$ & $3,829,597$ & Glycine hydroxymethyltransferase & ver/ph_18.1 & {$[48]$} \\
\hline VIT_18s0001g04680 & 18 & $3,938,582$ & $3,956,444$ & $\mathrm{RPG}$ related protein $1 \mathrm{RR} 1$ & ver/ph_18.1 & {$[44,46]$} \\
\hline VIT_18s0001g06430 & 18 & $4,806,981$ & $4,808,947$ & $\begin{array}{l}\text { Homeobox-leucine zipper protein } \\
\text { ATHB-6 }\end{array}$ & ver/ph_18.1 & {$[44,46,48]$} \\
\hline VIT_18s0001g07090 & 18 & $5,290,562$ & $5,293,561$ & Unknown protein & ver/ph_18.1 & {$[48]$} \\
\hline VIT_18s0001g12840 & 18 & $10,940,330$ & $10,945,165$ & $\begin{array}{l}\text { ADP-glucose pyrophosphorylase large } \\
\text { subunit CagpL2 }\end{array}$ & ver/ph_18.2 & {$[48]$} \\
\hline VIT_18s0001g13010 & 18 & $11,126,023$ & $11,129,236$ & $\begin{array}{l}\text { Mitogen-activated Protein Kinase } \\
\text { (VVMPK11) }\end{array}$ & ver/ph_18.2 & {$[48]$} \\
\hline VIT_18s0001g13200 & 18 & $11,256,653$ & $11,261,569$ & Cytokinin dehydrogenase 5 precursor & ver/ph_18.2 & {$[44,46]$} \\
\hline VIT_18s0001g14130 & 18 & $12,179,540$ & $12,181,647$ & Zinc finger ( $\mathrm{C} 2 \mathrm{H} 2$ type) family & ver/ph_18.2 & {$[44,46]$} \\
\hline VIT_18s0001g14360 & 18 & $12,337,145$ & $12,340,985$ & Tubulin beta-1 chain & ver/ph_18.2 & {$[44,46]$} \\
\hline VIT_18s0001g14440 & 18 & $12,432,955$ & $12,439,459$ & Molecular chaperone DnaJ & ver/ph_18.2 & {$[44,46]$} \\
\hline VIT_18s0001g14450 & 18 & $12,453,766$ & $12,456,583$ & Ferredoxin:nadp+ Oxidoreductase PETH & ver/ph_18.2 & {$[44,46]$} \\
\hline VIT_18s0001g15720 & 18 & $13,856,940$ & $13,861,020$ & Leucine Rich Repeat receptor-like kinase & ver/ph_18.2 & {$[44,46,48]$} \\
\hline VIT_18s0001g15730 & 18 & $13,865,318$ & $13,866,466$ & Dof zinc finger protein DOF3.5 & ver/ph_18.2 & {$[48]$} \\
\hline VIT_18s0076g00330 & 18 & $14,494,814$ & $14,503,181$ & $\begin{array}{l}\text { Basic Leucine Zipper Transcription } \\
\text { Factor (VvbZIP50) }\end{array}$ & ver/ph_18.2 & {$[48]$} \\
\hline VIT_18s0076g00310 & 18 & $14,550,818$ & $14,563,944$ & Translation initiation factor elF-5B & ver/ph_18.2 & {$[48]$} \\
\hline
\end{tabular}

${ }^{a}$ For each candidate physical position on the grape genome assembly as well as annotation is provided. Genes shown in the tables are selected by following slimGOs: GO:0000166, GO:0003676, GO:0003677, GO:0003682, GO:0003700, GO:0005102, GO:0005634, GO:0007154, GO:0007165, GO:0007275, GO:0009653, GO:0009719, GO:0009791, GO:0009908, GO:0016301, GO:0030154, GO:0038023, GO:0040007

${ }^{\mathrm{b}}$ Meta-QTL under which the candidate was found

'Reference of the transcriptomic study in which the candidate was found to be differentially expressed during veraison 
Taking advantage of this tool we have provided a compendium of all available QTL information that can be integrated at genetic level. Interestingly QTLs plotting revealed extensive co-locations across studies for each of the phenology related traits, besides downy mildew resistance, powdery mildew resistance, anthocyanin, drought stress, fertility, water use efficiency and growth, as well as for some berry and seeds related traits. However, studies addressing phenology are still few, negatively affecting the number of studies supporting each of the co-located QTLs. $R^{2}$ values of plotted QTLs, beside their distribution, suggest a highly polygenic nature for phenology related traits, with several QTLs involved, each of small effect, differently from other traits like pathogen resistance, seeds related traits and colour, all showing a more oligogenic architecture. More in detail, concerning veraison time four main regions located on LG 1 and 2 have so far emerged consistently. Interestingly, plotting on a unique consensus map of QTLs also allows inspection of co-location across traits and categories, which is especially relevant for complex traits. In this way QTL meta-analysis also allows genetic correlation among traits to be investigated [35, 92, 98, 99]. In a previous work a second round meta-QTL analysis was proposed for seed yield QTLs and co-located yield associated QTLs in rapeseed, which allowed "indicator" meta-QTLs contributing to the complex trait crop yield to be defined [100]. Indeed, QTL co-localization can be due to tight-linkage of QTL/genes playing different functions, but could also arise from pleiotropism. When pleiotropy is likely, it would also justify meta-analysis across traits, to further reduce the number of candidates [100]. Veraison time is expected to be strictly related to other phenological stages [9]. Accordingly, tests on the previously mentioned regions on LG 1 and LG 2 confirmed that, at least in some cases, comparable results are achieved when only veraison or all co-located phenology related traits are considered for the meta-analysis (see ver_2.1 and ver/ph_2.1 as an example). We therefore also attempted a similar approach for veraison QTLs co-located with other phenology QTLs, finally identifying a number of regions, of which the most relevant were those located on LGs 14, 16 and 18 . However, we are aware that these rely on the pleiotropic assumption, which could be not always satisfied. A recent QTL study based on a GBS SNP map also addressed the mapping of veraison time [101]. That study mainly aimed to discover and map stable QTLs across environments. A veraison QTL mapping on LG 16 between 5 and $24 \mathrm{cM}$, which corresponded to the region between 2 and $16 \mathrm{Mbp}$, was found, but was not consistent across environments. Interestingly, it partially overlapped the ver/ph_16.2 meta-QTL we derived here starting from a veraison QTL and its co-location to a flowering-veraison interval QTL. Beside the detailed analysis of phenology traits we have undertaken, our compendium now provides a useful tool for the inspection of co-location and meta-analysis for further traits in a similar way.

Transcriptomic studies have been also widely applied to characterize molecular changes associated to the onset of ripening, revealing, first of all, a massive transcriptomic rearrangement at veraison time [44, 49]. Among others, genes triggering such transition are expected to modulate their expression at this stage, although alternative regulative mechanisms cannot be excluded. We thus mined available transcriptomic profiles to i) identify the timing of such massive change, ii) select genes differentially expressed during this time in more varieties. Then, beside inspection of positional candidates underlying meta-QTLs, we propose to also integrate information about differential expression at veraison time, in order to prioritize candidates.

On LG 1 a veraison time QTL was previously mapped [25]. A more recent study [26] also mapped a QTL for veraison at this location, which allowed us to define the ver_1_1 meta-QTL. Flowering QTLs consistently overlapped at same location [22, 58] suggesting a possible control of veraison time through regulation of flowering time. Accordingly, candidates for the flowering time control mapped under this meta-QTL, like the PFT1 (phytochrome and flowering time 1) gene or a CONSTANS-like gene both controlling the photoperiodic flowering pathway in $A$. thaliana [102, 103]. Even though a possible impact of the genetic control of flowering on veraison time would reduce the relevance of candidates found by our transcriptomic approach, integration of transcriptomic data allowed to pinpoint 14 candidates, among which the VvRAV1 transcription factor, belonging to the plant-specific $R A V$ (RE$L A T E D$ TO ABI3 AND VP1) family. In Arabidopsis, RAV1 was shown to act as negative regulator of both development and flowering, probably in complexes with other co-repressors [104-106]. Interestingly, some members of this gene family were shown to modulate developmental transitions in response to temperature [107]. Moreover RAV1 was also shown to be negatively regulated by brassinosteroid and abscisic acid [104, $108]$, both hormones modulated at the onset of veraison time [1].

On LG 2 meta-QTL analysis of overlapping veraison QTLs allowed 3 main regions to be spotted. In the first of these regions flowering QTLs were also plotted [22], again supporting a possible regulation of veraison time through flowering, even though no genes controlling flowering time where found under this locus. Interestingly, the orthologous of the Arabidopsis YABBY1/FIL transcription factor, which directly activate the AtMYB75, 
a key regulator of anthocyanin biosynthesis [109], was found among candidates selected by the integration of expression data. Moreover, by looking at other functional categories possibly related to veraison time, a gene encoding for a vacuolar invertase 2, key enzyme of sugar metabolism in fruits during ripening [110], a stay-green protein 1 gene related to a gene shown to be involved in ripening in tomato [111], beside two pectin methylesterase inhibitor (PMEI) genes, were found as differentially expressed. These last belong to a gene family previously characterized in grape [112]. Their function is supposed to inhibit pectin methylesterase activity in pectin degradation, and may play a role in the beginning of ripening by regulating initial events such as softening and loss of turgor [113]. Interestingly, network analysis of gene expression profiles during berry ripening revealed PMEI among genes likely involved in triggering the major transcriptome reprogramming that occurs at veraison [44]. Within ver_2.2 meta-QTL, the most notable candidate considering both positional and expression data was the VvNAC13 transcription factor. This gene belongs to a wide family of transcription factors in grapevine [114]. Interestingly members of this family in tomato are involved in ethylene biosynthesis, reception and signalling during ripening [115]. Moreover, they were also already suggested as playing a crucial role in berry transcriptome modulation associated to veraison, according to network analysis of berry expression profiles [44]. However, in the same region, a gene encoding an atypical pseudo-response regulator (APRR2), involved in the circadian clock mechanism and contributing to fruit pigmentation and ripening in tomato [116], as well as two 1-aminocyclopropane-1-carboxylate oxidases, taking part in ethylene biosynthesis and ripening were also selected by our approach and represent promising candidates. Lastly, a cluster of Myb genes locates within ver_2.3 meta-QTL interval. These genes have previously been extensively characterized for their involvement in the transition to berry ripening, by regulating the accumulation of anthocyanins in the berry skin [93, 94]. This finding, thus, supports our approach, even though these genes are unlikely to be themselves the early triggers of ripening onset.

Other genomic regions were also proposed by previous studies for the genetic control of veraison time [22-26], among which the most relevant were mapping on LG 14, 16 and 18. By considering overlapping with other phenology related QTLs, followed by integration of transcriptomic data, we also selected candidates for these regions. The ver/ph_14.3 meta-QTL was computed from overlapping veraison QTL and flowering QTLs [23, 25, 58], and was accordingly highly enriched in candidates playing a role in the flowering transition control or fruit ripening, among which the most notable are Constans 2
(COL2), the feronia receptor-like kinase, a gene encoding a Brassinosteroid- 6 oxidase, a gene encoding a COBRA protein and the putative MADS-box FRUITFULL 2. Interestingly this last gene was recently shown to also contribute to modulate the onset of ripening in tomato at early fruit development, beside its involvement at later ripening stages [117]. A QTL previously mapped on LG 16 and explaining a large part of the genetic variance in the corresponding mapping population [26] partially co-localized to QTLs for the derived trait flowering-veraison interval $[22,23]$ and to the genomic region involved in veraison recently identified by the GBS-SNP map previously discussed [101]. According to our strategy, the original interval was reduced to two regions of about 3.3 Mbp overall, including 15 transcriptomic candidates. Interestingly, more recently, the SSR marker UDV052, mapping under the ver/ph_16.3 metaQTL close to the two candidates $\mathrm{ABC}$ transporter and an ERF transcription factor (19.1 Kbp and 56.9 Kbp respectively), was shown to be significantly associated to the early phenotype in a collection of different varieties, thus supporting our approach [118]. Lastly, three different veraison QTLs were mapped on LG18 [26]. Two of them partially co-located with flowering QTLs from an independent study, and one of them was overlapping also with a QTL for the flowering-veraison interval [23, 58]. Under the derived meta-QTLs, ver/ph_18.1 and ver/ ph_18.2, spanning a still large region, we selected 74 transcriptomic candidates among which 19 were encoding proteins involved in regulation of gene expression, signalling or development. Candidates involved in carbohydrate metabolism, including especially a hexose (HT2) and a sucrose transporter (SUT2-2), putatively modulating sucrose signalling, or candidates encoding for genes for cell wall degradation (like a glucanase and a galactosidase, as examples), were also among those selected.

\section{Conclusions}

By building a grape consensus genetic map anchored to the genome assembly a comprehensive overview about genomic distribution of several QTLs from published studies and their co-location both inside traits as well as across related traits was provided. Extensive co-localization was evident especially for phenology related traits. Four veraison meta-QTLs located on LG 1 and 2 were found. Moreover several additional meta-QTLs, computed from co-localization of veraison QTLs with alternative phenology related QTLs, were derived, among which most relevant on LG 14, 16 and 18. Integration of meta-QTLs with expression data from prior transcriptomic studies allowed to select a set of 272 candidate genes for the genetic control of the veraison transition, reducing by about 20 and 10 times the genes proposed so far by either only genetic or transcriptomic approaches. Among these candidates 78 
genes were involved in regulation of gene expression, signal transduction or development. Specific relevant candidates according to their annotation have been discussed. Further studies can now test and eventually validate the putative involvement of these candidates in the genetic control of the veraison transition during berry development.

\section{Methods}

\section{Collection of QTL studies and QTLs data}

All published QTL experiments on grapevine were collected, mainly by using the public database PubMed (https://www.ncbi.nlm.nih.gov/pubmed/) and searching for "grape" and "QTL". QTL experiments were selected if relying on genetic maps including shared SSR markers and if all required information for further analysis were available (Additional file 1). Individual genetic linkage map including marker names and position in $\mathrm{cM}$ were transcribed from all experiments. Consensus map was selected, when this was provided. Parental maps were included only if consensus maps were not available (see Additional file 1 for more details). Data about mapped QTLs were also transcribed, in particular start and end position of the QTL, confidence interval in $\mathrm{cM}$, peak of the QTL in $\mathrm{cM}$, QTL associated variance explained value $\left(R^{2}\right)$ and the size/type of the population that was used for mapping the QTL. All QTLs were included, independently of their phenotypic scoring system, score thresholds, LOD/ variance values or years of observation. Details on original QTL short names, as well as a short description, are given in Additional file 2. Only for the veraison trait, on which this work is mainly focused, further details about the different phenotypic scoring systems in the different original publication have been collected (Additional file 19). For all other QTLs we refer to the original publication for more details about the phenotypic scoring. QTLs were attributed to eight main categories including related traits, to aid storage and further studies. All markers and QTLs information were properly formatted to be imported into BioMercator v4.2 software [87].

\section{Building of a grapevine consensus map}

Name of the markers in each map were manually curated in order to correct misspellings and find synonyms. Indeed, to combine the individual maps into a consensus map, markers' name requires to be consistent. Each map file was imported in BioMercator v4.2 [87] and each linkage group was oriented according to the reference map published in Doligez et al., 2006 [88]. Linkage groups that did not share at least two markers with others were removed from the analysis, since they could not be properly oriented. This led to a different number of input maps for each linkage group depending on the chromosome. InfoMap command in the software was used to evaluate markers order and consistency between each pair. In case of inversions, occurrence of inverted markers in all the maps was evaluated and the less represented marker across all maps was removed to retain most frequent common marker. When no more inversions were left, the command ConsMap was used to build the consensus map in a single step chromosome by chromosome, without providing any reference.

\section{Anchoring to the grapevine genome by in silico mapping of GCM markers}

Grape Consensus Map (GCM) markers' sequences were downloaded from original publications and blasted against the 12X.v2 assembly of the grapevine genome using the website https://urgi.versailles.inra.fr/blast/. An anchor map was created including all univocally mapping GCM markers with corresponding base pairs positions. The anchor map was uploaded to BioMercator v4.2 and the option "New genome version" was used to anchor the GCM to the grapevine genome from the .gff3 file (https://urgi.versailles.inra.fr/Species/Vitis/Annotations). This allows recovering of physical intervals for any feature (like QTLs or meta-QTLs), through BioMercator using a software internal formula (Yannick De Oliveira, personal communication).

\section{QTL projection}

Each QTL was associated to the genetic map were it was originally mapped. The command QTLProj in the BioMercator v4.2 software was applied to project the QTLs of the component maps to the consensus map. The command performs a homothetic projection of the original QTL to the consensus map based on flanking markers and using a scaling rule. This is applied only when flanking markers are found where the ratio of the distance of these markers to the confidence interval of the QTL that is being projected is not reduced by a factor greater than 0.25 . Default options were kept for the analysis. Consensus QTL maps were extracted for each trait and manually inspected for QTLs co-location across populations. All regions spanned by QTLs for a same trait mapped in different mapping populations were recorded. Significance of QTLs co-localization was calculated as described in [92].

\section{QTL meta-analysis}

The meta-QTL analysis was performed by using the QTLClust command in BioMercator v4.2 software when at least two overlapping QTLs belonging to the same trait were found. Redundant QTLs, that is, QTLs on same position from same study, which could overestimate 
the effect of that QTL in the analysis were pruned retaining that with highest $R^{2}$ prior the analysis [35]. The meta-analysis was executed selecting the Veyrieras algorithm [28]. Optimal number of meta-QTLs explaining overlapping QTLs was statistically determined by choosing the most likely model, as computed by the software according to five different tests. Indeed the software performs the clustering of the input overlapping QTLs for a trait and allows determining the most likely number of meta-QTLs, calculating models for as many QTLs up to the number of the input QTLs and providing values for each model for five different criterion: the AIC (Akaike information criterion), the AICc, the AIC3, the BIC (Bayesian information criterion) and the AWE (average weight of evidence). Best model was selected as the one minimizing values for the highest number of criterion which represents the optimal number of clusters that best explain the observed QTL distribution. MQTLView command allows to graphically represent the meta-QTLs according to the selected model. A second round of meta-QTL analysis was performed as described in [35] by merging veraison QTLs and other overlapping phenology related traits for meta-QTL analysis.

Physical intervals for each meta-QTL were computed as previously explained through anchoring to grape genome assembly 12X.v2 in the BioMercator v4.2 software and underlying candidate genes retrieved including their functional annotation according to CRIBIv1 annotation (http://genomes.cribi.unipd.it/gb2/gbrowse/ public/vitis_vinifera_v2/). Gene ontology annotations were retrieved by using the getBM function of the Bioconductor biomaRt (2.38.0) package. Vitis vinifera Ensembl database was used and candidate genes were annotated with GO slim accessions.

\section{Transcriptomic data integration}

The grapevine expression atlas [49] was used to retrieve expression in different grape organs and exclude candidate genes never expressed in berry, rachis or seeds. RNA-Seq gene expression data along berry development were retrieved from three studies [44, 46, 48]. Ninetynine berry RNA-Seq profiles for the cultivars Pinot Noir collected in triplicates in the years 2012, 2013 and 2014 around the time of veraison [48] were retrieved. Genes with FPKM (fragments per kilobase of exon model per million reads mapped) values lower than 1 in at least 2 replicates at all time-points were considered as never expressed and removed from the dataset. Expression of early "biomarkers" of veraison transition [48] was inspected at early time points during berry development before veraison to identify the interval in each year when the transcriptomic rearrangement associated to veraison first occurs. Genes showing highest modulation in their expression across this interval in at least 2 years were selected by inspecting FPKM values and considered as transcriptomic candidates to be joined to genes differentially expressed across veraison in all varieties as defined in $[44,46]$. Finally transcriptomic candidates positioned under meta-QTLs were selected.

\section{Supplementary information}

Supplementary information accompanies this paper at https://doi.org/10. 1186/s12864-019-6124-0.

Additional file 1. List of publications including grapevine QTL studies selected as suitable for integration of QTLs data. For each publication are reported reference of the genetic map used in the original publication, details about the cross population used for QTL mapping and the total number and categories of QTLs included in the analysis.

Additional file 2. List of phenotypes scored in the selected QTL studies, grouped according to the study. The list includes the original QTL short name attributed in the reference to each phenotype, as well as a short description. The main trait for which the phenotype was considered to be a descriptor and the trait category are also indicated for each phenotype.

Additional file 3. Overview of selected grapevine QTLs included in the analysis. (a) Number of QTLs for each trait, shown separately for the 8 different trait categories. (b) Number of QTL studies addressing each of the traits, shown separately for each category. Studies addressing more traits are repeatedly count in each category, so plotted numbers of QTLS studies for each category is redundant. The number of unique studies for each category is shown in brackets. Colour code for each trait is given in the legend table.

Additional file 4. The grape consensus genetic map built from 39 grape linkage maps. The table includes physical marker position if available, for anchoring to the grapevine genome assembly.

Additional file 5. Graphical overview of the consensus genetic map. Additional file 6. Number of maps used for the construction of each consensus linkage group.

Additional file 7. Spearman's rank correlation values of each pairwise comparison between markers' order of each single component map and with the consensus map. References for each single component map are reported in Additional file 6.

Additional file 8. Consensus QTL maps for each of the 34 traits built by projection onto the consensus map of QTLs from the selected 47 QTL studies. Each map is provided in a separate sheet and for each the whole and short QTL name, as well the genetic position information and physical position information obtained through marker anchoring of the map to the genome are given. Details about QTL short names abbreviations are in Additional file 2.

Additional file 9. Circular plots of consensus QTL maps built by plotting of QTLs on the consensus map. Circular plots are grouped according to categories: (a) abiotic stress response, (b) cluster related traits, (c) berry morphology, (d) berry metabolites, (e) pathogen resistance, (f) seed related traits, $(\mathrm{g})$ vegetative traits. QTLS are shown in the internal side of each chromosome. Genetic regions spanned by QTLs confirmed in independent population are highlighted by a bar on the outer side of the chromosomes. Colour code for each trait is given in the legend table.

Additional file 10. List of QTLs showing at least partial overlapping with similar QTLs from independent studies. Whole and short QTL names, as well as the genetic position information and physical position information obtained through marker anchoring of the map to the genome are given. Details about QTL short names abbreviations are in Additional file 2.

Additional file 11. Meta-QTLs calculated from veraison QTLs overlapping with other phenology QTLs on LG1 and LG2 providing meta-QTLs in high agreement to meta-QTLs calculated only from veraison QTLS. 
Additional file 12. Lists of candidate genes in ver meta-QTLs intervals with the corresponding genomic positions derived by anchoring to the genome and CRIBlv1 annotation. GO annotation was included only for genes with GOs related to expression regulation, signalling or development (GO:0000166, GO:0003676, GO:0003677, GO:0003682, GO:0003700, GO:0005102, GO:0005634, GO:0007154, GO:0007165, GO:0007275, GO:0009653, GO:0009719, GO:0009791, GO:0009908, GO:0016301, GO:0030154, GO:0038023, GO:0040007) representing most relevant positional candidates for veraison regulation according to functional annotation.

Additional file 13. Lists of candidate genes in ver/ph meta-QTLs intervals with the corresponding genomic positions derived by anchoring to the genome and CRIBIv1 annotation. GO annotation was included only for genes with GOs related to expression regulation, signalling or development (GO:0000166, GO:0003676, GO:0003677, GO:0003682,

GO:0003700, GO:0005102, GO:0005634, GO:0007154, GO:0007165, GO:0007275, GO:0009653, GO:0009719, GO:0009791, GO:0009908, GO:0016301, GO:0030154, GO:0038023, GO:0040007) representing most relevant positional candidates for veraison regulation according to functional annotation.

Additional file 14. Meta-QTLs calculated from 28 overlapping QTLs from 5 independent studies for the well characterized anthocyanin colour trait mapping at the colour locus on LG2.

Additional file $\mathbf{1 5}$ Lists of candidate genes in the 7 anthocyanin metaQTLs intervals identified by meta-QTLs analysis as reported in Additional file 14. Positional information were derived by map anchoring to the genome and CRIBIv1 annotation. This list includes the VVMYBA1 and VVMYBA2 genes well known for involvement in anthocyanin biosynthesis and colour determination in grape, thus supporting the meta-QTLs approach applied in this study.

Additional file 16. Number of differentially expressed biomarker genes obtained by comparison of expression levels at each time point before visual veraison and next one, until visual veraison. Each time point is expressed as days before visual veraison. Number of early "biomarkers" of veraison transition as defined in [48] found as differentially expressed across intervals are given. The interval across which the highest number of biomarkers was differentially expressed represents the timing when early transcriptomic rearrangement associated to the veraison starts to occur in each year.

Additional file 17. Whole list of transcriptomic candidates derived by studies of expression profiles along berry development [44], [46], [48] including positional information and functional annotation. Information about the original study in which they were selected and about their eventual prioritization through network analysis of expression profiles ("switch genes") or selection as "biomarkers" according to profile analysis in original studies is included.

Additional file 18. List of 272 genes selected by integrating the list of transcriptomic candidates and positional information from the meta-QTL analysis. Positional information (Chr and position) derived by map anchoring to the genome, functional annotation and information about the transcriptomic study in which each candidate was first reported are included for each selected candidate in the table. Table 5 represents a subset of this table, including, among these candidates, those involved in signalling, development or regulation of gene expression.

Additional file 19. Phenotypic scoring details for selected veraison QTLS used in the work. Details about the phenotypic scoring have been collected from original publications and reported here alongside with QTL short name, QTL description and the reference publication.

\section{Abbreviations}

Ac: Total acidity; AlC: Akaike information criterion; At: Tartaric acid; AWE: Average weight of evidence; BB: Bud break; B-B: February-budbreak/ Bud; B-F: Budbreak-flowering/Flo; BIC: Bayesian information criterion; Bp: Basepair; Bpc: Brixper cluster; Chr: Chromosome; Cl: Confidence interval; cM: centiMorgan; Cma: Fruit maturation period; FB: Flowering beginning; FBL: Time of full bloom; FPKM: Fragments per kilobase of exon model per million reads mapped; F-R: Flowering ripening interval; FS: Start of flowering: FT: Flowering time; F-V: Flowering-veraison interval; Fw: Flowering;
GBS: Genotyping by sequencing; GCM: Grape Consensus Map; GO: Gene ontologies; LG: Linkage group; Ma: Malic acid; QTL: Quantitative trait loci; R: Ripening; RDA: Ripening date; Rp: Ripening; RT: Ripening time; SNP: Single nucleotide polymorphism; Sp: Sprouting; ssc: solubile solids concentration; SSR: Simple sequence repeats; ta: total acid; Tar/Ma: Ratio of tartaric acid to malic acid; Tss/Ac: Ratio of total soluble solids to total acidity; VB: Veraison beginning; VE: Veraison end; ver: veraison meta-QTLs; ver/ph: meta-QTL from veraison QTLs and other phenology related overlapping QTLs; VP: Veraison period; Vr: Veraison; V-R: Veraison ripening interval; Vr-Rp: Veraison-ripening period; VT: Veraison time

\section{Acknowledgements}

We thank Prof. Mario Pezzotti for useful discussion and critical reading of the manuscript, Prof. Nicola Vitulo for helpful indications on bioinformatic topics, Dott.ssa Marianna Fasoli for information on transcriptomic dataset.

\section{Authors' contributions}

PD and DB performed all analysis and interpreted all data. SZ and GBT supported the analysis of transcriptomic data. ZI helped preparing datasets and contributed to interpretation of data. DB and PD wrote the manuscript. SZ, GBT and ZI edited the manuscript. All authors read and approved the final manuscript.

\section{Funding}

The study was supported by the BANDO Joint Project 2015 and 2016 from University of Verona, by POR FESR 2014-2020. DGR n. 1139 19.07.2017 Azione 1.1.4. Project VIT-VIVE from Veneto Region and COST Action INTEGRAPE CA17111 from EU. The funding bodies had no role in the design of the study and collection, analysis, interpretation of data and in writing the manuscript.

\section{Availability of data and materials}

All genetic and QTL data used in this article are referenced in Table 1 and Additional file 1. The datasets including the consensus genetic map and all consensus QTL maps compiled and supporting the conclusions of this work are included within the article and its additional files. Transcriptomic datasets used referred to the atlas grapevine transcriptomic dataset performed by microarray [49], the grapevine berry RNA-Seq data for red and white skinned varieties [46], and the grapevine berry RNA-Seq data on Pinot noir [48], and are available in a Minimum Information About a Microarray Experiment (MIAME)-compliant database (Gene Expression Omnibus) at the National Center for Biotechnology Information, with the GSE36128, GSE62744 and GSE62745 and GSE98923, respectively.

\section{Ethics approval and consent to participate}

Not applicable.

\section{Consent for publication}

Not applicable.

\section{Competing interests}

The authors declare that they have no competing interests.

\section{Author details}

${ }^{1}$ Department of Biotechnology, University of Verona, Strada le Grazie 15, 37134 Verona, Italy. ${ }^{2}$ Present address: Department of Diagnostics and Public Health, Section of Pathology, University and Hospital Trust of Verona, Verona, Italy.

Received: 12 April 2019 Accepted: 20 September 2019 Published online: 15 October 2019

\section{References}

1. Conde C, Silva P, Fontes N, Dias A, Tavares R, Sousa M, Agasse A, Delrot S, Gerós H. Biochemical changes throughout grape berry development and fruit and wine quality. Food. 2007;1(1):1-22.

2. Duchêne $E$, Huard F, Dumas V, Schneider C, Merdinoglu D. The challenge of adapting grapevine varieties to climate change. Clim Res. 2010;41(3):193-204.

3. Wolkovich EM, de Cortazar-Atauri IG, Morales-Castilla I, Nicholas KA, Lacombe T. From pinot to Xinomavro in the world's future wine-growing regions. Nat Clim Chang. 2018;8(1):29-37. 
4. Jones VG, White MA, Cooper OR, Storchmann K. Climate change and global wine quality. Clim Chang. 2005;73(3):319-43.

5. Mori K, Goto-Yamamoto N, Kitayama M, Hashizume K. Loss of anthocyanins in red-wine grape under high temperature. J Exp Bot. 2007;58(8):1935-45.

6. Rienth M, Torregrosa L, Sarah G, Ardisson M, Brillouet JM, Romieu C. Temperature desynchronizes sugar and organic acid metabolism in ripening grapevine fruits and remodels their transcriptome. BMC Plant Biol. 2016;16(1):164.

7. Sweetman C, Sadras VO, Hancock RD, Soole KL, Ford CM. Metabolic effects of elevated temperature on organic acid degradation in ripening Vitis vinifera fruit. J Exp Bot. 2014;65(20):5975-88.

8. Jones GV, Davis RE. Climate influences on grapevine phenology, grape composition, and wine production and quality for Bordeaux, France. Am J Enol Vitic. 2000;51(3):249-61.

9. Duchêne E, Schneider C. Grapevine and climatic changes: a glance at the situation in Alsace. Agron Sustain Dev. 2005;25(1):93-9.

10. Webb LB, Whetton PH, Barlow EWR. Modelled impact of future climate change on the phenology of winegrapes in Australia. Aust J Grape Wine Res. 2007;13(3):165-75

11. Tomasi D, Jones VG, Giust M, Lovat L, Gaiotti F. Grapevine phenology and climate change: relationships and trends in the Veneto region of Italy for 1964-2009. Am J Enol Vitic. 2011;62(3):329-39.

12. van Leeuwen $C$, Darriet $P$. The impact of climate change on viticulture and wine quality. J Wine Econ. 2016;11(01):150-67.

13. Pons A, Allamy L, Schüttler A, Rauhut D, Thibon C, Darriet P, Ollat N. What is the expected impact of climate change on wine aroma compounds and their precursors in grape? J Int Sci Vigne Vin. 2017;51(2):141-6.

14. Ramos MC, Jones VG. Relationships between cabernet sauvignon phenology and climate in two Spanish viticultural regions: observations and predicted future changes. J Agric Sci. 2019:156(9):1-11.

15. Parker A, de Cortázar-Atauri IG, Chuine I, Barbeau G, Bois B, Boursiquot JM, Cahurel JY, Claverie M, Dufourcq T, Gény L, et al. Classification of varieties for their timing of flowering and veraison using a modelling approach: a case study for the grapevine species Vitis vinifera L. Agric For Meteorol. 2013;180:249-64.

16. Hannah L, Roehrdanz PR, Ikegami M, Shepard AV, Shaw MR, Tabor G, Zhi L, Marquet PA, Hijmans RJ. Climate change, wine, and conservation. Proc Natl Acad Sci U S A. 2013;110(17):6907-12.

17. van Leeuwen $C$, Schultz HR, de Cortazar-Atauri IG, Duchene E, Ollat N, Pieri P, Bois B, Goutouly JP, Quenol H, Touzard JM, et al. Why climate change will not dramatically decrease viticultural suitability in main wine-producing areas by 2050. Proc Natl Acad Sci U S A. 2013;110(33):E3051-2.

18. Fraga H, García de Cortázar Atauri I, Malheiro AC, Santos JA. Modelling climate change impacts on viticultural yield, phenology and stress conditions in Europe. Glob Chang Biol. 2016;22(11):3774-88.

19. Santillán D, Iglesias A, La Jeunesse I, Garrote L, Sotes V. Vineyards in transition: a global assessment of the adaptation needs of grape producing regions under climate change. Sci Total Environ. 2019;657:839-52.

20. De Cortázar-Atauri IG, Duchêne É, Destrac-Irvine A, Barbeau G, De Rességuier L, Lacombe T, Parker AK, Saurin N, Van Leeuwen C, Ollat N. Grapevine phenology in France: from past observations to future evolutions in the context of climate change. J Int Sci Vigne Vin. 2017;51(2):115-26.

21. Bigard A, Berhe DT, Maoddi E, Sire Y, Boursiquot JM, Ojeda H, Peros JP, Doligez A, Romieu C, Torregrosa L. Vitis vinifera L. Fruit Diversity to Breed Varieties Anticipating Climate Changes. Front Plant Sci. 2018;9:455.

22. Costantini L, Battilana J, Lamaj F, Fanizza G, Grando M. Berry and phenology-related traits in grapevine (Vitis viniferaL.): From Quantitative Trait Loci to underlying genes. BMC Plant Biol. 2008;8(1):38.

23. Duchêne E, Butterlin G, Dumas V, Merdinoglu D. Towards the adaptation of grapevine varieties to climate change: QTLS and candidate genes for developmental stages. Theor Appl Genet. 2012;124(4):623-35.

24. Grzeskowiak L, Costantini L, Lorenzi S, Grando MS. Candidate loci for phenology and fruitfulness contributing to the phenotypic variability observed in grapevine. Theor Appl Genet. 2013;126(11):2763-76.

25. Fechter I, Hausmann L, Zyprian E, Daum M, Holtgräwe D, Weisshaar B, Töpfer R. QTL analysis of flowering time and ripening traits suggests an impact of a genomic region on linkage group 1 in Vitis. Theor Appl Genet. 2014;127(9):1857-72.

26. Zyprian E, Ochßner I, Schwander F, Šimon S, Hausmann L, Bonow-Rex M, Moreno-Sanz P, Grando MS, Wiedemann-Merdinoglu S, Merdinoglu D, et al. Quantitative trait loci affecting pathogen resistance and ripening of grapevines. Mol Gen Genomics. 2016;291(4):1573-94.

27. Goffinet B, Gerber S. Quantitative trait loci: a meta-analysis. Genetics. 2000; 155(1):463-73.
28. Veyrieras JB, Goffinet B, Charcosset A. MetaQTL: a package of new computational methods for the meta-analysis of QTL mapping experiments. BMC Bioinformatics. 2007;8(1):49.

29. Chardon F, Virlon B, Moreau L, Falque M, Joets J, Decousset L, Murigneux A Charcosset A. Genetic architecture of flowering time in maize as inferred from quantitative trait loci meta-analysis and synteny conservation with the rice genome. Genetics. 2004;168(4):2169-85.

30. Salvi S, Sponza G, Morgante M, Tomes D, Niu X, Fengler KA, Meeley R, Ananiev EV, Svitashev S, Bruggemann E, et al. Conserved noncoding genomic sequences associated with a flowering-time quantitative trait locus m maize. Proc Natl Acad Sci U S A. 2007;104(27):11376-81.

31. Salvi S, Corneti S, Bellotti M, Carraro N, Sanguineti MC, Castelletti S, Tuberosa $R$. Genetic dissection of maize phenology using an intraspecific introgression library. BMC Plant Biol. 2011;11:4

32. Hung HY, Shannon LM, Tian F, Bradbury PJ, Chen C, Flint-Garcia SA, McMullen MD, Ware D, Buckler ES, Doebley JF, et al. ZmCCT and the genetic basis of day-length adaptation underlying the postdomestication spread of maize. Proc Natl Acad Sci U S A. 2012;109(28):E1913-21.

33. Daware VA, Srivastava R, Singh AK, Parida SK, Tyagi AK. Regional association analysis of MetaQTLs delineates candidate grain size genes in Rice. Front Plant Sci. 2017;8:807.

34. Said JI, Song M, Wang H, Lin Z, Zhang X, Fang DD, Zhang J. A comparative meta-analysis of QTL between intraspecific Gossypium hirsutum and interspecific $\mathrm{G}$. hirsutum $\times$ G. barbadense populations. Mol Gen Genomics. 2015;290(3):1003-25.

35. Danan S, Veyrieras J-B, Lefebvre V. Construction of a potato consensus map and QTL meta-analysis offer new insights into the genetic architecture of late blight resistance and plant maturity traits. BMC Plant Biol. 2011;11(1):16.

36. Van K, McHale LK. Meta-Analyses of QTLs associated with protein and oil contents and compositions in soybean [Glycine max (L.) Merr.] Seed. Int J Mol Sci. 2017;18(6):1180.

37. Izquierdo P, Astudillo C, Blair MW, labal AM, Raatz B, Cichy KA. Meta-QTL analysis of seed iron and zinc concentration and content in common bean (Phaseolus vulgaris L.). Theor Appl Genet. 2018;131(8):1645-58.

38. Jaillon O, Aury JM, Noel B, Policriti A, Clepet C, Casagrande A, Choisne N, Aubourg S, Vitulo N, Jubin C, et al. The grapevine genome sequence suggests ancestral hexaploidization in major angiosperm phyla. Nature. 2007:449(7161):463-7.

39. Deluc LG, Grimplet J, Wheatley MD, Tillett RL, Quilici DR, Osborne C, Schooley DA, Schlauch KA, Cushman JC, Cramer GR. Transcriptomic and metabolite analyses of cabernet sauvignon grape berry development. BMC Genomics. 2007;8:429.

40. Pilati S, Perazzolli M, Malossini A, Cestaro A, Demattè L, Fontana P, Dal Ri A, Viola R, Velasco R, Moser C. Genome-wide transcriptional analysis of grapevine berry ripening reveals a set of genes similarly modulated during three seasons and the occurrence of an oxidative burst at vèraison. BMC Genomics. 2007:8(1):428.

41. Fortes AM, Agudelo-Romero P, Silva MS, Ali K, Sousa L, Maltese F, Choi YH, Grimplet J, Martinez-Zapater JM, Verpoorte R, et al. Transcript and metabolite analysis in Trincadeira cultivar reveals novel information regarding the dynamics of grape ripening. BMC Plant Biol. 2011;11(1):149.

42. Dal Santo S, Tornielli GB, Zenoni S, Fasoli M, Farina L, Anesi A, Guzzo F, Delledonne M, Pezzotti M. The plasticity of the grapevine berry transcriptome. Genome Biol. 2013;14(6):r54.

43. Cramer GR, Ghan R, Schlauch KA, Tillett RL, Heymann H, Ferrarini A, Delledonne M, Zenoni S, Fasoli M, Pezzotti M. Transcriptomic analysis of the late stages of grapevine (Vitis vinifera cv. Cabernet Sauvignon) berry ripening reveals significant induction of ethylene signaling and flavor pathways in the skin. BMC Plant Biol. 2014;14(1):370.

44. Palumbo MC, Zenoni S, Fasoli M, Massonnet M, Farina L, Castiglione F, Pezzotti M, Paci P. Integrated network analysis identifies fight-Club nodes as a class of hubs encompassing key putative switch genes that induce major transcriptome reprogramming during grapevine development. Plant Cell Online. 2014;26(12):4617-35.

45. Dal Santo S, Zenoni S, Poni S, Paci P, Bellincontro A, Tornielli GB, Silvestroni $\mathrm{O}$, Fasoli M, Matarese F, Frioni T, et al. Distinct transcriptome responses to water limitation in isohydric and anisohydric grapevine cultivars. BMC Genomics. 2016;17(1):815.

46. Massonnet M, Fasoli M, Tornielli GB, Altieri M, Sandri M, Zuccolotto P, Paci P, Gardiman M, Zenoni S, Pezzotti M. Ripening transcriptomic program in red and White grapevine varieties correlates with berry skin anthocyanin accumulation. Plant Physiol. 2017;174(4):2376-96. 
47. Wong DCJ, Schlechter R, Vannozzi A, Höll J, Hmmam I, Bogs J, Tornielli GB, Castellarin SD, Matus JT. A systems-oriented analysis of the grapevine R2R3MYB transcription factor family uncovers new insights into the regulation of stilbene accumulation. DNA Res. 2016;23(5):451-66.

48. Fasoli M, Richter CL, Zenoni S, Bertini E, Vitulo N, Dal Santo S, Dokoozlian N, Pezzotti M, Tornielli GB. Timing and order of the molecular events marking the onset of berry ripening in grapevine. Plant Physiol. 2018;178(3):1187-206.

49. Fasoli M, Dal Santo S, Zenoni S, Tornielli GB, Farina L, Zamboni A, Porceddu A, Venturini L, Bicego M, Murino V, et al. The grapevine expression atlas reveals a deep transcriptome shift driving the entire plant into a maturation program. Plant Cell. 2012;24(9):3489-505.

50. Azuma A, Ban Y, Sato A, Kono A, Shiraishi M, Yakushiji H, Kobayashi S. MYB diplotypes at the color locus affect the ratios of tri/di-hydroxylated and methylated/non-methylated anthocyanins in grape berry skin. Tree Genet Genomes. 2015;11(2). https://doi.org/10.1007/s11295-015-0855-0.

51. Ban Y, Mitani N, Hayashi T, Sato A, Azuma A, Kono A, Kobayashi S. Exploring quantitative trait loci for anthocyanin content in interspecific hybrid grape (Vitis labruscana X Vitis vinifera). Euphytica. 2014;198(1):101-14.

52. Ban Y, Mitani N, Sato A, Kono A, Hayashi T. Genetic dissection of quantitative trait loci for berry traits in interspecific hybrid grape (Vitis labruscana $\times$ Vitis vinifera). Euphytica. 2016;211(3):295-310.

53. Bayo Canha A: Genetic analysis of traits of interest in Vitis vinifera using a progeny of wine grapes: Monastrell x Syrah. 2016.PhD Thesis.

54. Bellin D, Peressotti E, Merdinoglu D, Wiedemann-Merdinoglu S, AdamBlondon AF, Cipriani G, Morgante M, Testolin R, Di Gaspero G. Resistance to Plasmopara viticola in grapevine 'Bianca' is controlled by a major dominant gene causing localised necrosis at the infection site. Theor Appl Genet. 2009;120(1):163-76.

55. Bert PF, Bordenave L, Donnart M, Hevin C, Ollat N, Decrooca S. Mapping genetic loci for tolerance to lime-induced iron deficiency chlorosis in grapevine rootstocks (Vitis sp.). Theor Appl Genet. 2013;126(2):451-73.

56. Blasi $P$, Blanc S, Wiedemann-Merdinoglu S, Prado E, Rühl EH, Mestre P, Merdinoglu D. Construction of a reference linkage map of Vitis amurensis and genetic mapping of Rpv8, a locus conferring resistance to grapevine downy mildew. Theor Appl Genet. 2011;123(1):43-53.

57. Cabezas JA, Cervera MT, Ruiz-Garcia L, Carreno J, Martinez-Zapater JM. A genetic analysis of seed and berry weight in grapevine. Genome. 2006; 49(12):1572-85.

58. Carreño Ruiz I: Identificación de regiones cromosómicas implicadas en el control genético de caracteres de interés para la mejora genética de la uva de mesa. 2012. PhD Thesis.

59. Correa J, Mamani M, Munoz-Espinoza C, Laborie D, Munoz C, Pinto M, Hinrichsen P. Heritability and identification of QTLs and underlying candidate genes associated with the architecture of the grapevine cluster (Vitis vinifera L.). Theor Appl Genet. 2014;127(5):1143-62.

60. Correa J, Ravest G, Laborie D, Mamani M, Torres E, Muñoz C, Pinto M, Hinrichsen P. Quantitative trait loci for the response to gibberellic acid of berry size and seed mass in tablegrape (Vitis vinifera L.). Aust J Grape Wine Res. 2015;21(3):496-507.

61. Correa J, Mamani M, Munoz-Espinoza C, Gonzalez-Aguero M, Defilippi BG, Campos-Vargas R, Pinto M, Hinrichsen P. New stable QTLs for berry firmness in table grapes. Am J Enol Vitic. 2016;67(2):212-7.

62. Costantini L, Malacarne G, Lorenzi S, Troggio M, Mattivi F, Moser C, Grando MS. New candidate genes for the fine regulation of the colour of grapes. J Exp Bot. 2015;66(15):4427-40.

63. Coupel-Ledru A, Lebon E, Christophe A, Doligez A, Cabrera-Bosquet L, Pechier $P$, Hamard $P$, This $P$, Simonneau T. Genetic variation in a grapevine progeny (Vitis vinifera L. cvs GrenachexSyrah) reveals inconsistencies between maintenance of daytime leaf water potential and response of transpiration rate under drought. J Exp Bot. 2014;65(21):6205-18.

64. Coupel-Ledru A, Lebon E, Christophe A, Gallo A, Gago P, Pantin F, Doligez A, Simonneau T. Reduced nighttime transpiration is a relevant breeding target for high water-use efficiency in grapevine. Proc Natl Acad Sci U S A. 2016:113(32):8963-8

65. Doligez A, Bertrand Y, Dias S, Grolier M, Ballester J-F, Bouquet A, This P. QTLS for fertility in table grape (Vitis vinifera L.). Tree Genet Genomes. 2010;6(3): 413-22.

66. Doligez A, Bertrand Y, Farnos M, Grolier M, Romieu C, Esnault F, Dias S, Berger G, Francois P, Pons T, et al. New stable QTLs for berry weight do not colocalize with QTLs for seed traits in cultivated grapevine (Vitis vinifera L.). BMC Plant Biol. 2013;13:217.
67. Duchêne E, Butterlin G, Claudel P, Dumas V, Jaegli N, Merdinoglu D. A grapevine (Vitis vinifera L.) deoxy-d-xylulose synthase gene colocates with a major quantitative trait loci for terpenol content. Theor Appl Genet. 2009; 118(3):541-52.

68. Garris A, Clark L, Owens C, Mckay S, Luby J, Mathiason K, Fennell A. Mapping of photoperiod-induced growth cessation in the wild grape Vitis riparia. J Am Soc Hortic Sci. 2009;134(2):261-72.

69. Guo YS, Xue RY, Lin H, Su K, Zhao YH, Zhendong L, Ma HF, Shi GL, Niu ZZ, Li K, et al. Genetic analysis and QtI mapping for fruit skin Anthocyanidin in grape (Vitis vinifera). Pak J Bot. 2015;47(5):1765-71.

70. Herzog K, Wind R, Topfer R. Impedance of the grape berry cuticle as a nove phenotypic trait to estimate resistance to botrytis Cinerea. Sensors-Basel. 2015;15(6):12498-512.

71. Huang YF, Doligez A, Fournier-Level A, Le Cunff L, Bertrand Y, Canaguier A, Morel C, Miralles V, Veran F, Souquet JM, et al. Dissecting genetic architecture of grape proanthocyanidin composition through quantitative trait locus mapping. BMC Plant Biol. 2012;12:30.

72. Huang YF, Vialet $S$, Guiraud JL, Torregrosa L, Bertrand $Y$, Cheynier V, This $P$ Terrier N. A negative MYB regulator of proanthocyanidin accumulation, identified through expression quantitative locus mapping in the grape berry. New Phytol. 2014;201(3):795-809.

73. Malacarne G, Costantini L, Coller E, Battilana J, Velasco R, Vrhovsek U, Grando MS, Moser C. Regulation of flavonol content and composition in (SyrahxPinot noir) mature grapes: integration of transcriptional profiling and metabolic quantitative trait locus analyses. J Exp Bot. 2015;66(15):4441-53.

74. Marguerit E, Brendel O, Lebon E, Van Leeuwen C, Ollat N. Rootstock control of scion transpiration and its acclimation to water deficit are controlled by different genes. New Phytol. 2012;194(2):416-29.

75. Mejia N, Gebauer M, Munoz L, Hewstone N, Munoz C, Hinrichsen P. Identification of QTLs for seedlessness, berry size, and ripening date in a. seedless X seedless table grape progeny. Am J Enol Vitic. 2007;58(4):499-507.

76. Mejia N, Soto B, Guerrero M, Casanueva X, Houel C, Miccono Mde L, Ramos $R$, Le Cunff L, Boursiquot JM, Hinrichsen P, et al. Molecular, genetic and transcriptional evidence for a role of VVAGL11 in stenospermocarpic seedlessness in grapevine. BMC Plant Biol. 2011;11:57.

77. Moreira FM, Madini A, Marino R, Zulini L, Stefanini M, Velasco R, Kozma P, Grando MS. Genetic linkage maps of two interspecific grape crosses (Vitis spp.) used to localize quantitative trait loci for downy mildew resistance. Tree Genet Genomes. 2010;7(1):153-67.

78. Ochssner I, Hausmann L, Topfer R. Rpv14, a new genetic source for Plasmopara viticola resistance conferred by Vitis cinerea. Vitis. 2016; 55(2):79-81.

79. Rex M, Welter $L$, Topfer R, Zyprian E. Dissecting the genetic determinants of powdery mildew resistance in grape. Acta Hortic. 2014;1046:79-84.

80. Zhang J, Hausmann L, Eibach R, Welter LJ, Topfer R, Zyprian EM. A framework map from grapevine V3125 (Vitis vinifera 'Schiava grossa' $x$ 'Riesling') x rootstock cultivar 'Borner' (Vitis riparia $x$ Vitis cinerea) to localize genetic determinants of phylloxera root resistance. Theor Appl Genet. 2009; 119(6):1039-51.

81. Schwander F, Eibach R, Fechter I, Hausmann L, Zyprian E, Topfer R. Rpv10: a new locus from the Asian Vitis gene pool for pyramiding downy mildew resistance loci in grapevine. Theor Appl Genet. 2012;124(1):163-76.

82. van Heerden CJ, Burger $P$, Vermeulen A, Prins R. Detection of downy and powdery mildew resistance QTL in a 'regent' $\times$ 'RedGlobe' population. Euphytica. 2014;200(2):281-95.

83. Viana AP, Riaz S, Walker MA. Genetic dissection of agronomic traits within a segregating population of breeding table grapes. Genet Mol Res. 2013;12(2): 951-64.

84. Welter LJ, Göktürk-Baydar N, Akkurt M, Maul E, Eibach R, Töpfer R, Zyprian EM. Genetic mapping and localization of quantitative trait loci affecting fungal disease resistance and leaf morphology in grapevine (Vitis vinifera L). Mol Breed. 2007:20(4):359-74.

85. Zhao YH, Guo YS, Lin H, Liu ZD, Ma HF, Guo XW, Li K, Yang XX, Niu ZZ, Shi GG. Quantitative trait locus analysis of grape weight and soluble solid content. Genet Mol Res. 2015;14(3):9872-81.

86. Zhao YH, Su K, Guo YH, Ma HF, Guo XW. Molecular genetic map construction and QTL analysis of fruit maturation period in grapevine. Genet Mol Res. 2016;15(2). https://doi.org/10.4238/gmr.15028040.

87. Sosnowski O, Charcosset A, Joets J. Biomercator V3: an upgrade of genetic map compilation and quantitative trait loci meta-analysis algorithms. Bioinformatics. 2012;28(15):2082-3. 
88. Doligez A, Adam-Blondon AF, Cipriani G, Di Gaspero G, Laucou V, Merdinoglu D, Meredith CP, Riaz S, Roux C, This P. An integrated SSR map of grapevine based on five mapping populations. Theor Appl Genet. 2006;113(3):369-82.

89. Riaz S, Krivanek AF, Xu K, Walker MA. Refined mapping of the Pierce's disease resistance locus, $P d R 1$, and sex on an extended genetic map of Vitis rupestris $\times$ V. arizonica. Theor Appl Genet. 2006;113(7):1317-29.

90. Venuti S, Copetti D, Foria S, Falginella L, Hoffmann S, Bellin D, Cindrić P, Kozma P, Scalabrin S, Morgante M, et al. Historical introgression of the downy mildew resistance gene Rpv12 from the Asian species Vitis amurensis into grapevine varieties. PLoS One. 2013;8(4):e61228.

91. Canaguier A, Grimplet J, Di Gaspero G, Scalabrin S, Duchêne E, Choisne N, Mohellibi N, Guichard C, Rombauts S, Le Clainche I, et al. A new version of the grapevine reference genome assembly (12X.v2) and of its annotation (VCost.v3). Genom Data. 2017;14:56-62.

92. Truntzler M, Barriere $Y$, Sawkins MC, Lespinasse D, Betran J, Charcosset $A$ Moreau L. Meta-analysis of QTL involved in silage quality of maize and comparison with the position of candidate genes. Theor Appl Genet. 2010; 121(8):1465-82.

93. Kobayashi S, Goto-Yamamoto N, Hirochika H. Retrotransposon-induced mutations in grape skin color. Science (New York, NY). 2004;304(5673):982.

94. Walker AR, Lee E, Bogs J, McDavid DAJ, Thomas MR, Robinson SP. White grapes arose through the mutation of two similar and adjacent regulatory genes. Plant J. 2007:49(5):772-85.

95. Salvi S, Tuberosa R. The crop QTLome comes of age. Curr Opin Biotechnol. 2015:32:179-85

96. Martinez AK, Soriano JM, Tuberosa R, Koumproglou R, Jahrmann T, Salvi S. Yield QTLome distribution correlates with gene density in maize. Plant Sci. 2016;242:300-9.

97. Arcade A, Labourdette A, Falque M, Mangin B, Chardon F, Charcosset A, Joets J. BioMercator: integrating genetic maps and QTL towards discovery of candidate genes. Bioinformatics. 2004;20(14):2324-6.

98. Xiang K, Reid LM, Zhang ZM, Zhu XY, Pan GT. Characterization of correlation between grain moisture and ear rot resistance in maize by QTL metaanalysis. Euphytica. 2012;183(2):185-95.

99. Badji A, Otim M, Machida L, Odong T, Kwemoi DB, Okii D, Agbahoungba S, Mwila N, Kumi F, Ibanda A, et al. Maize combined insect resistance genomic regions and their co-localization with Cell Wall constituents revealed by tissue-specific QTL meta-analyses. Front Plant Sci. 2018:9:895.

100. Shi J, Li R, Qiu D, Jiang C, Long Y, Morgan C, Bancroft I, Zhao J, Meng J. Unraveling the complex trait of crop yield with quantitative trait loc mapping in Brassica napus. Genetics. 2009;182(3):851-61.

101. Houel C, Chatbanyong R, Doligez A, Rienth M, Foria S, Luchaire N, Roux C, Adivèze $A$, Lopez $G$, Farnos $M$, et al. Identification of stable QTLs for vegetative and reproductive traits in the microvine (Vitis vinifera L.) using the $18 \mathrm{~K}$ Infinium chip. BMC Plant Biol. 2015;15(1):205.

102. Putterill J, Robson F, Lee K, Simon R, Coupland G. The CONSTANS gene of arabidopsis promotes flowering and encodes a protein showing similarities to zinc finger transcription factors. Cell. 1995;80(6):847-57.

103. Cerdan PD, Chory J. Regulation of flowering time by light quality. Nature. 2003;423(6942):881-5.

104. Hu YX, Wang YH, Liu XF, Li JY. Arabidopsis RAV1 is down-regulated by brassinosteroid and may act as a negative regulator during plant development. Cell Res. 2004;14(1):8-15.

105. Zhao L, Luo QL, Yang CL, Han YP, Li WB. A RAV-like transcription factor controls photosynthesis and senescence in soybean. Planta. 2008;227(6):1389-99.

106. Matias-Hernandez L, Aguilar-Jaramillo AE, Marin-Gonzalez E, Suarez-Lopez P, Pelaz S. RAV genes: regulation of floral induction and beyond. Ann Bot. 2014;114(7):1459-70

107. Marin-Gonzalez E, Matias-Hernandez L, Aguilar-Jaramillo AE, Lee JH, Ahn JH, Suarez-Lopez P, Pelaz S. SHORT VEGETATIVE PHASE up-regulates TEMPRANILLO2 floral repressor at low ambient temperatures. Plant Physiol. 2015;169(2):1214-24

108. Fu M, Kang HK, Son SH, Kim SK, Nam KH. A subset of arabidopsis RAV transcription factors modulates drought and salt stress responses independent of ABA. Plant Cell Physiol. 2014;55(11):1892-904.

109. Boter M, Golz JF, Gimenez-lbanez S, Fernandez-Barbero G, Franco-Zorrilla JM, Solano R. FILAMENTOUS FLOWER is a direct target of JAZ3 and modulates responses to Jasmonate. Plant Cell. 2015;27(11):3160-74.

110. Qin GZ, Zhu Z, Wang WH, Cai JH, Chen Y, Li L, Tian SP. A tomato vacuolar Invertase inhibitor mediates sucrose metabolism and influences fruit ripening. Plant Physiol. 2016;172(3):1596-611
111. Barry CS, McQuinn RP, Chung MY, Besuden A, Giovannoni JJ. Amino acid substitutions in homologs of the STAY-GREEN protein are responsible for the green-flesh and chlorophyll retainer mutations of tomato and pepper. Plant Physiol. 2008;147(1):179-87.

112. Lionetti V, Raiola A, Mattei B, Bellincampi D. The grapevine VvPMEl1 gene encodes a novel functional pectin Methylesterase inhibitor associated to grape berry development. PLoS One. 2015;10(7):e0133810.

113. Castellarin SD, Gambetta GA, Wada H, Krasnow MN, Cramer GR, Peterlunger E, Shackel KA, Matthews MA. Characterization of major ripening events during softening in grape: turgor, sugar accumulation, abscisic acid metabolism, colour development, and their relationship with growth. J Exp Bot. 2016;67(3):709-22.

114. Wang N, Zheng Y, Xin H, Fang L, Li S. Comprehensive analysis of NAC domain transcription factor gene family in Vitis vinifera. Plant Cell Rep. 2013, 32(1):61-75.

115. Kou X, Liu C, Han L, Wang S, Xue Z. NAC transcription factors play an important role in ethylene biosynthesis, reception and signaling of tomato fruit ripening. Mol Gen Genomics. 2016;291(3):1205-17.

116. Pan Y, Bradley G, Pyke K, Ball G, Lu C, Fray R, Marshall A, Jayasuta S, Baxter C, van Wijk R, et al. Network inference analysis identifies an APRR2-like gene linked to pigment accumulation in tomato and pepper fruits. Plant Physiol. 2013;161(3):1476-85.

117. Wang R, Angenent GC, Tavano ECR, Martinelli AP, de Maagd RA, Lammers $M$. Re-evaluation of transcription factor function in tomato fruit development and ripening with CRISPR/Cas9-mutagenesis. Sci Rep. 2019; 9(1):1696.

118. Zyprian E, Trapp O, Eibach R, Trapp O, Schwander F, Töpfer R. Grapevine breeding under climate change: applicability of a molecular marker linked to véraison sensor-assisted phenotyping of grape bunch architecture. Vitis J Grapevine Res. 2018;57(3):119-23.

\section{Publisher's Note}

Springer Nature remains neutral with regard to jurisdictional claims in published maps and institutional affiliations.

Ready to submit your research? Choose BMC and benefit from:

- fast, convenient online submission

- thorough peer review by experienced researchers in your field

- rapid publication on acceptance

- support for research data, including large and complex data types

- gold Open Access which fosters wider collaboration and increased citations

- maximum visibility for your research: over $100 \mathrm{M}$ website views per year

At $\mathrm{BMC}$, research is always in progress.

Learn more biomedcentral.com/submission 